\title{
Structure sensitivity of the oxidative activation of methane over MgO model catalysts: II. Nature of active sites and reaction mechanism
}

Pierre Schwach, Neil Hamilton, Maik Eichelbaum, Lukas Thum, Thomas Lunkenbein,

Robert Schlögl, and Annette Trunschke*

Department of Inorganic Chemistry, Fritz-Haber-Institut der Max-Planck-Gesellschaft e.V., Faradayweg 4-6, 14195 Berlin, Germany.

schwachp@,fhi-berlin.mpg.de current e-mail address: hamilton.neilg@googlemail.com me@fhi-berlin.mpg.de lunkenbein@,fhi-berlin.mpg.de thum@fhi-berlin.mpg.de acsek@,fhi-berlin.mpg.de trunschke@fhi-berlin.mpg.de 


\begin{abstract}
A series of pure, nano-structured magnesium oxides prepared by different synthesis techniques that show different initial, but similar steady-state activity in the oxidative coupling of methane (OCM) [1] has been studied by infrared and photoluminescence spectroscopy in the dehydroxylated state before the reaction and after catalysis. The abundance of structural defects, in particular mono-atomic steps, on the dehydroxylated $\mathrm{MgO}$ surface characterized by a band in the FTIR spectrum of adsorbed CO at $2146 \mathrm{~cm}^{-1}$ and Lewis acid/base pairs probed by co-adsorption of $\mathrm{CO}$ and $\mathrm{CH}_{4}$ correlate with the initial rates of both methane consumption and $\mathrm{C}_{2+}$ hydrocarbon formation. Infrared spectroscopy evidences strong polarization of $\mathrm{C}-\mathrm{H}$ bonds due to adsorption of methane on dehydroxylated $\mathrm{MgO}$ surfaces that contain a high number of mono-atomic steps. It is postulated that these sites effectively promote intermolecular charge transfer between adsorbed methane and weakly adsorbed oxygen that leads to the dissociation of one $\mathrm{C}-\mathrm{H}$ bond in the methane molecule and simultaneous formation of a superoxide species. Heterolytic splitting of $\mathrm{C}-\mathrm{H}$ bonds in the presence of oxygen at the surface of dehydroxylated $\mathrm{MgO}$ already at room temperature has been proven by the appearance of an EPR signal associated with superoxide species that are located in close vicinity to a proton. With time on stream, $\mathrm{MgO}$ sinters and loses activity. The deactivation process involves the depletion of mono-atomic steps and the reconstruction of the $\mathrm{MgO}$ termination under formation of polar and faceted surfaces.
\end{abstract}

\title{
Keywords
}

$\mathrm{MgO}$; oxidative coupling; methane; active site; infrared; photoluminescence; EPR; CO adsorption; defects; reaction mechanism 


\section{Introduction}

Activation of $\mathrm{C}-\mathrm{H}$ bonds in the chemically rather inert methane molecule is an academically challenging goal with prospective industrial significance in view of the demands to make new resources, like natural gas, accessible for the manufacture of base chemicals and intermediates. In a kinetic study,[1] we investigated the oxidative coupling of methane (OCM) over pure magnesium oxide involving five differently prepared model catalysts that differ in particular in the nano-structure of the surface. The performance of dehydroxylated $\mathrm{MgO}$ at the beginning of the reaction (at $t=0$ ), and the kinetics of catalyst deactivation strongly depend on initial particle morphology and surface texture, whereas similar catalyst properties are finally approached in the steady-state. The "MgO inherent" steady-state activity is, however, rather low.[1] Therefore, it appears desirable to identify the nature of the highly active surface sites on the surface of freshly dehydroxylated $\mathrm{MgO}$ and to explore options to stabilize this productive state of the catalyst. Tuning the catalyst performance using rational design approaches also requires knowledge about the deactivation mechanism to decide whether stabilization strategies may have any reasonable prospects.

The kinetic investigation of $\mathrm{MgO}$ in OCM (Part I of this work)[1] implies a dynamic change of the reaction mechanism(s) with time on stream. Electron microscopy indicates an impact of structural defects on the surface of $\mathrm{MgO}$ on reactivity, and evidences significant changes in morphology and termination of the primary catalyst particles with time.[1] Hence, the current part of the work (Part II) is devoted to the characterization of type and relative abundance of structural defects, i.e., coordinatively unsaturated sites, at the surface of freshly dehydroxylated $\mathrm{MgO}$ prepared by different synthesis techniques. FTIR spectroscopy of adsorbed probe molecules,[2, 3] photoluminescence, and EPR spectroscopy [4-7] have been proven beneficial in the analysis of $\mathrm{MgO}$, and have been applied in the present investigation. 
The results of the spectroscopic analysis will be linked to the kinetic data acquired in Part I.[1]

Based on sound spectroscopic evidence we postulate that weakly adsorbed methane and oxygen undergo a concerted reaction mechanism that involves direct electron transfer from a $\mathrm{C}-\mathrm{H}$ bond of the methane to the oxygen molecule. The dehydroxylated $\mathrm{MgO}$ surface assists the polarization of the methane molecule by providing highly specific adsorption sites at mono-atomic steps and the underlying terrace that facilitates the reaction of methane with weakly adsorbed oxygen effectively. These sites, however, disappear with time on stream under reaction conditions of oxidative methane coupling. Possible mechanistic scenarios in the deactivated state of $\mathrm{MgO}$ under steady-state conditions will be discussed.

\section{Experimental}

\subsection{Catalysts and chemicals}

The present study was performed using the same catalysts that have been analyzed in the kinetic investigation in Part I [1] including commercially available ultra-pure MgO from Alfa Aesar (C-MgO), hydrothermally treated $\mathrm{C}-\mathrm{MgO}$ applying ambient pressure (HT-MgO) or elevated pressure using a microwave autoclave (MW-MgO), $\mathrm{MgO}$ prepared by sol-gel synthesis ( $\mathrm{SG}-\mathrm{MgO})$, and $\mathrm{MgO}$ prepared by combustion of metallic $\mathrm{Mg}$ in air ( $\mathrm{S}-\mathrm{MgO})$. The synthesis methods and the microstructural properties of the catalysts determined by nitrogen adsorption, X-ray diffraction, and electron microscopy have been described in detail in Part I.[1]

The purity of nitrogen, argon, and oxygen (Westfalen AG) used for spectroscopic characterization of the catalysts was $99.999 \%$. Methane and CO used for the FTIR experiments (purity $99.999 \%$ ) were delivered by MESSER. Methane- $\mathrm{d}_{4}$ (purity 99.98\%) was purchased by Sigma-Aldrich. 


\subsection{Infrared spectroscopy}

FTIR spectroscopy was carried out using a Perkin-Elmer Spectrum 100 spectrometer equipped with a MCT detector. The spectra were recorded at a resolution of $4 \mathrm{~cm}^{-1}$ accumulating 64 scans. Self-supported wafers were obtained by pressing the powdered catalysts under a pressure of $123 \mathrm{MPa}$. The wafers were transferred into an IR cell that is connected to a vacuum system, which allows to achieve a residual pressure of ca. $1 \times 10^{-5} \mathrm{~Pa}$. Prior to the adsorption of gases, the catalysts were heated in $2 \cdot 10^{4} \mathrm{~Pa} \mathrm{O}_{2}$ at $1128 \mathrm{~K}$ (heating rate $10 \mathrm{~K} \cdot \mathrm{min}^{-1}$ ) for $3 \mathrm{~h}$. For low-temperature adsorption experiments, the sample was subsequently cooled in vaccum to room temperature. Then, the sample chamber was charged with $200 \mathrm{~Pa}$ partial pressure of He used as heat transfer agent and cooled to $77 \mathrm{~K}$ with liquid nitrogen. At first, a background spectrum was recorded in $200 \mathrm{~Pa}$ of $\mathrm{He}$ by removing the wafer from the beam. This spectrum serves as background for the spectrum of the pure, freshly pretreated catalyst. The adsorption measurements were performed in the following order: (1) addition of $\mathrm{CH}_{4}$ at various pressures up to an equilibrium pressure of $200 \mathrm{~Pa} \mathrm{CH}_{4}$ (total pressure $400 \mathrm{~Pa} \mathrm{CH}_{4}+\mathrm{He}$ ); (2) evacuation at $77 \mathrm{~K}$ until the baseline was fully recovered; (3) addition of $200 \mathrm{~Pa} \mathrm{He}$ and stepwise adsorption of $\mathrm{CO}$ up to partial pressure of $200 \mathrm{~Pa} \mathrm{CO}$ (total pressure $400 \mathrm{PaCO}+\mathrm{He}$ ); (4) subsequent adsorption of $\mathrm{CH}_{4}$ up to partial pressure of $200 \mathrm{~Pa} \mathrm{CH}_{4}$ (total pressure $600 \mathrm{PaCO}+\mathrm{CH}_{4}+\mathrm{He}$ ). Difference spectra were obtained through subtraction of the absorbance spectrum of the catalyst in $200 \mathrm{~Pa} \mathrm{He}$ from the absorbance spectrum of the sample in presence of the gases. All presented spectra have been normalized to the post-measurement areal density of the sample wafer.

\subsection{EPR spectroscopy}

Continuous wave (c.w.) X-band EPR spectra were recorded at liquid nitrogen temperature on a Bruker ESP 300 E spectrometer equipped with a X-band microwave bridge Bruker ER 042 MRH E. A Bruker ER 4116 DM resonator operating in the TE 102 mode (f $~ 9.5 \mathrm{GHz}$ ) was 
used. The spectra were recorded with a modulation frequency of $100 \mathrm{kHz}$ and a microwave power of $2 \mathrm{~mW}$. The frequency and $\mathrm{g}$ values were calibrated using the ${ }^{52} \mathrm{Cr}$ line at $\mathrm{g}=1.9796$ of $\mathrm{Cr}^{3+}$-doped $\mathrm{MgO}$ as internal standard placed inside the resonator. The catalyst samples were filled in a quartz cell equipped with Teflon Duran ${ }^{\circledR}$ valves and connected to a vacuum system that allows the dosing of gases. Before EPR measurements, the $\mathrm{MgO}$ catalysts were activated at $1073 \mathrm{~K}$ under dynamic vacuum $\left(10^{-6}-10^{-7} \mathrm{mbar}\right)$ for 3 hours. Methane $\left(\mathrm{p}=1 \cdot 10^{4}\right.$ $\mathrm{Pa}$ ) and oxygen $(\mathrm{p}=1000 \mathrm{~Pa})$ were subsequently dosed at room temperature and the system was equilibrated under these conditions for $30 \mathrm{~min}$. Then, the cell was evacuated, the Teflon Duran ${ }^{\circledR}$ valves were closed, and the evacuated cell was put into the EPR resonator equipped with a quartz Dewar vessel containing liquid $\mathrm{N}_{2}$ to cool the sample to $77 \mathrm{~K}$ and perform the EPR measurement. EPR spectra were simulated using the Matlab ${ }^{\circledR}$ implementation Easyspin[8] in order to obtain a best fit for g-tensors and hyperfine coupling constants.

\subsection{Diffuse reflectance spectroscopy}

The in situ UV-VIS experiments were performed in the range between 200 and $800 \mathrm{~nm}$ using a PerkinElmer Lambda 650 spectrometer equipped with a diffuse reflectance accessory (Praying Mantis, Harrick). The catalysts were investigated in powdered form in an environmental chamber attachment (Harrick HVC-VUV-4) using Spectralon ${ }$ as white standard. In this chamber, the catalysts were pretreated in situ at $923 \mathrm{~K}$ for 30 min under vacuum (lower than $1 \cdot 10^{-3} \mathrm{~Pa}$ ). Subsequently, the chamber was cooled in dynamic vacuum and the spectra were recorded at $313 \mathrm{~K}$.

\subsection{Electron microscopy}

High-resolution transmission electron microscopy (HRTEM) images were recorded on a Cscorrected FEI Titan 80-300 at an acceleration voltage of $300 \mathrm{kV}$. 


\subsection{Photoluminescence}

Photoluminescence spectra were recorded on a PerkinElmer LS-55 spectrometer at room temperature under dynamic vacuum at a pressure lower than $5 \cdot 10^{-6} \mathrm{mbar}$. The spectrometer was equipped with a red sensitive photomultiplier R928 from Hamamatsu Photonics that allows detection of emissions in the range between 200 und $900 \mathrm{~nm}$. The spectra were recorded with an emission and excitation slit opening of $2.5 \mathrm{~nm}$, a scanning speed of 20 $\mathrm{nm} / \mathrm{min}$ and an emission filter of $350 \mathrm{~nm}$ in order to suppress direct light scattering from excitation. The catalyst powder was located in a flat SUPRASIL ${ }^{\circledR}$ quartz cell from HellmaAnalytics with a path length of $2 \mathrm{~mm}$. The cell was connected to a vacuum and gas dosing line. Before measurement the catalysts were heated at $1073 \mathrm{~K}$ in dynamic vacuum for 6 hours. Before catalytic testing the materials were measured as powder, while the used catalysts were pressed into pellets of the size of the photoluminescence cell.

\section{Results}

The magnesium oxide catalysts studied in oxidative coupling of methane in Part I differ in their morphology.[1] The trend in specific surface area is not directly related to the mean crystallite size determined by XRD indicating that surface texturing contributes substantially to the surface area measured by nitrogen adsorption. However, sintering phenomena are observed for all catalysts after use in the oxidative coupling of methane at $1073 \mathrm{~K}$ for approximately 300 hours time on stream. The domain size determined by XRD increases substantially except in the case of $\mathrm{S}-\mathrm{MgO}$, that shows a slight size reduction of the initially very large particles.[1] In agreement with a similar size of the coherently scattering domains in the used catalysts, the specific surface area of all used catalysts is similar and varies between 7 and $12 \mathrm{~m}^{2} \cdot \mathrm{g}^{-1}$. Sintering is also visible by TEM and SEM.[1] After catalysis, the morphology of the primary particles is much more rounded. The characteristic sharp edges and corners of the cubic structure have disappeared and pseudo $\{110\}$ and $\{111\}$ faces 
consisting of stepped edges between $\{100\}$ planes and numerous corners have formed. The sintering is accompanied by catalyst deactivation. With the aim to learn more about potential active sites on the surface of fresh, dehydroxylated $\mathrm{MgO}$ and their depletion under reaction conditions, transmission infrared spectroscopy was used. $\mathrm{CO}$ adsorption at $77 \mathrm{~K}$ provides information on coordinatively unsaturated $\mathrm{Mg}^{2+}$ adsorption sites (Lewis acid sites), while adsorption of methane probes both acidic (cationic) and basic (anionic) sites. Co-adsorption of methane and carbon monoxide reveals the relative abundance of acid-base and basic sites.

\subsection{IR spectroscopy}

\subsubsection{Calcined MgO}

\subsubsection{CO adsorption}

Adsorption of carbon monoxide at low temperatures results in the appearance of carbonyl bands that are shifted to higher energy compared to the $\mathrm{C}-\mathrm{O}$ stretching mode of the free $\mathrm{CO}$ molecule at $2143 \mathrm{~cm}^{-1}$ due to formation of $\sigma$-donor bonds via the carbon atom of the CO molecule to coordinatively unsaturated surface cations.[9] The shift to higher wavenumber is a result of the Stark effect associated with the positive electric field of the adsorptive cation. When no d-electrons are involved, the shift is proportional to the strength of the electric field sensed by CO.[10, 11] As a reasonable first approximation, the effective electric field experienced by $\mathrm{CO}$ adsorbed on a cationic site is a result of the contribution of the cation and the anions of the first coordination sphere. Thus, when the number of anions surrounding a $\mathrm{Mg}^{2+}$ adsorption site decreases, the negative contribution to the electric field decreases and, hence, the effective positive field experienced by the adsorbed $\mathrm{CO}$ increases.

Bands arising below $2000 \mathrm{~cm}^{-1}$ are attributed to carbonite anions or similar polymeric structures reflecting the strong basic character of the $\mathrm{MgO}$ surface.[12, 13] These species are formed by interaction of the $\mathrm{CO}$ molecule with coordinatively unsaturated oxygen ions.[12] 
Fig. 1 exemplarily presents infrared spectra of $\mathrm{CO}$ adsorbed on $\mathrm{C}-\mathrm{MgO}$ at $77 \mathrm{~K}$ and shows the development of $\mathrm{C}=\mathrm{O}$ stretching bands as a function of increasing $\mathrm{CO}$ pressure. At this low adsorption temperature, only negligible traces of carbonite species were observed (Fig. 1A). In the following, the spectra are, therefore, presented and analyzed exclusively in the range between 2100 and $2200 \mathrm{~cm}^{-1}$. At low pressures, i.e. up to ca. $7 \mathrm{~Pa}$, a broad feature due to superimposed contributions of bands at 2146, 2157, and $2164 \mathrm{~cm}^{-1}$ is discernible (Fig. 1B). With increasing equilibrium pressure of $\mathrm{CO}$, the bands at $2146 \mathrm{~cm}^{-1}$ and $2164 \mathrm{~cm}^{-1}$ are more and more obscured by the most intense band that shifts from $2157 \mathrm{~cm}^{-1}$ to $2152 \mathrm{~cm}^{-1}$. Spoto et al.[2] discussed two sets of bands located at 2150-2145 $\mathrm{cm}^{-1}$, and $2180-2160 \mathrm{~cm}^{-1}$, respectively, formed upon adsorption of $\mathrm{CO}$ on the $\mathrm{MgO}$ surface at $60 \mathrm{~K}$. The $2150-2145 \mathrm{~cm}^{-1}$ bands exhibit a maximum located at ca. $2150 \mathrm{~cm}^{-1}$ with a shoulder at $2140 \mathrm{~cm}^{-1}$, which are similar to the features observed at 2156 and $2146 \mathrm{~cm}^{-1}$ in Fig. 1B. Such signals are reported to be strongly attenuated as the $\mathrm{MgO}$ crystals become more ordered and are found to be completely absent from spectra of nearly perfect well-ordered $\mathrm{MgO}$ cubelets prepared by combustion of metallic Mg ("smoke synthesis").[2] The signal located at $2146 \mathrm{~cm}^{-1}$ is assigned to a $\mathrm{CO}$ species bonded to $\mathrm{Mg}^{2+}{ }_{4 \mathrm{C}}-\mathrm{Mg}^{2+} 5 \mathrm{C}$ pairs at mono-atomic step edges, either through both the carbon end coordinated to a $\mathrm{Mg}^{2+}{ }_{4 \mathrm{C}}$ site at the edge and the oxygen end coordinated to a $\mathrm{Mg}^{2+}{ }_{5 \mathrm{C}}$ site located at the subjacent terrace or through the carbon end only as bridged species.[2] Computational studies indicate that $\mathrm{CO}$ coordination via carbon only in form of a bridged complex is more likely.[14] Trionfetti et al. observed this band also after $\mathrm{CO}$ adsorption on $\mathrm{Li} / \mathrm{MgO}$ catalysts, but with increasing $\mathrm{Li}$ content the contribution of the step sites decreases,[15] which is in agreement of the "ironing" effect of alkali additives.[16] 

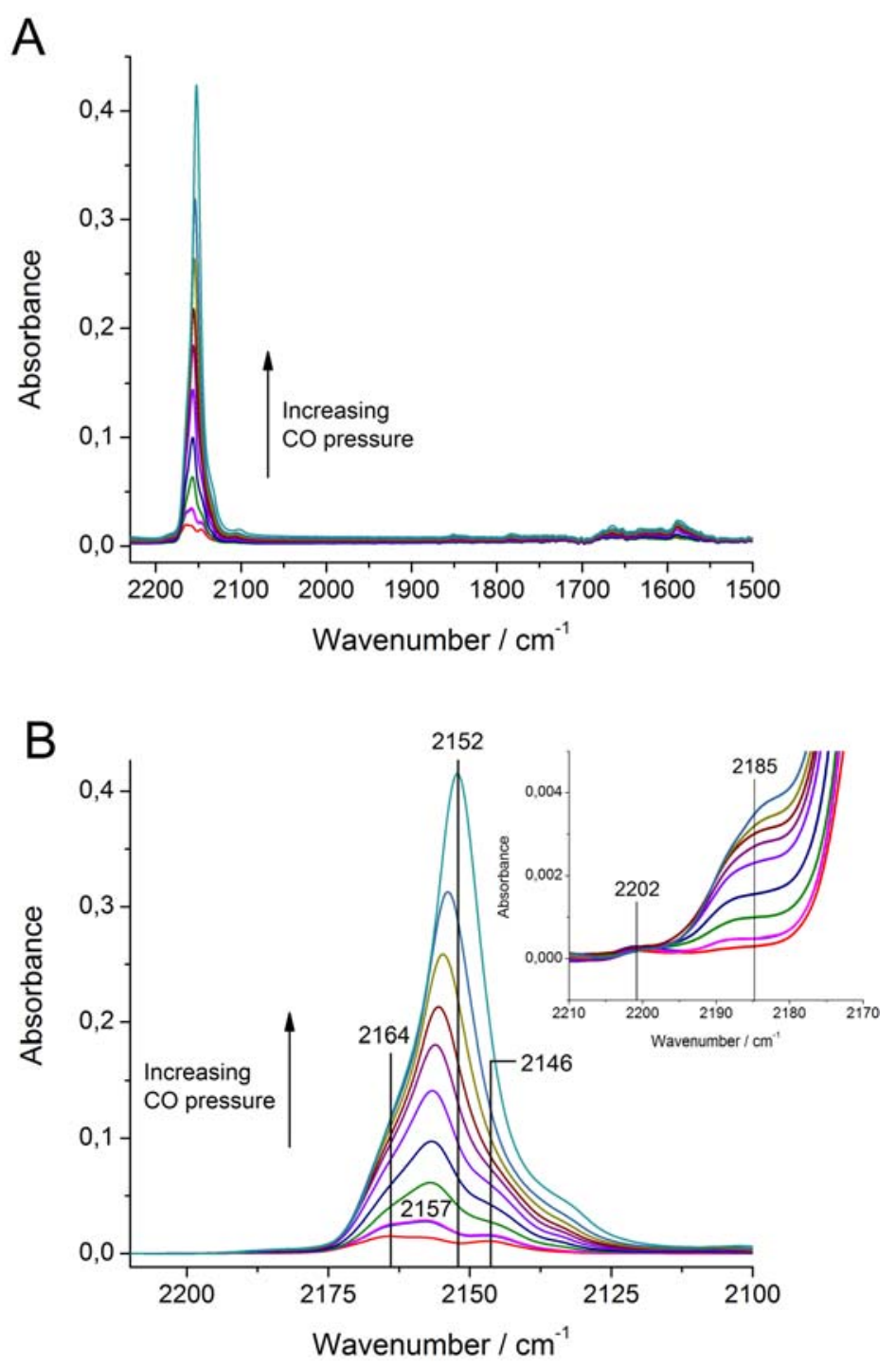

Fig. 1. IR spectra of $\mathrm{CO}$ adsorbed on $\mathrm{C}-\mathrm{MgO}$ at $\mathrm{T}=77 \mathrm{~K}$ with increasing equilibrium pressure from $\mathrm{p}=2.9 \mathrm{~Pa}$ to $\mathrm{p}=210 \mathrm{~Pa}$. (A) Entire range of carbonyl and carbonite vibrations (B) Evolution of carbonyl bands as a function of the $\mathrm{CO}$ equilibrium pressure. Inset: Enlarged representation of carbonyl bands assigned to $\mathrm{CO}$ adsorbed on 3-fold coordinated $\mathrm{Mg}^{2+}$ cations.

The band located at $2157-2152 \mathrm{~cm}^{-1}$ has been assigned to $\mathrm{Mg}^{2+}{ }_{5 \mathrm{C}}$ on (100) terrace sites.[2] Note that the feature observed at ca. $2146 \mathrm{~cm}^{-1}$ in Fig. 1B is swallowed up and finally completely obscured by the band associated with terrace sites located at $2152 \mathrm{~cm}^{-1}$ at higher equilibrium pressures. This observation is consistent with the findings of Spoto et al.,[2] who argued that $\mathrm{CO}$ is adsorbed to pairs of $\mathrm{Mg}^{2+}$ cations at low pressures in bridged configuration, while at higher pressure this configuration is displaced by a $1: 1$ ratio between $\mathrm{Mg}^{2+}$ centres 
and adsorbed CO. Features located in the range between $2180-2160 \mathrm{~cm}^{-1}$ are typically assigned to terminal $\mathrm{CO}$ adsorbed on $\mathrm{Mg}^{2+}{ }_{4 \mathrm{C}}$ centres, $[2,15]$ which occur at the surface as edges either of mono-atomic or multi-atomic steps, respectively. We therefore assign the band located at $2164 \mathrm{~cm}^{-1}$ in Fig. 1B to CO adsorbed on edge sites. Spoto et al. reported a band located at $2205-2200 \mathrm{~cm}^{-1}$ at low CO pressure that shows a red shift towards $2185 \mathrm{~cm}^{-1}$ at higher $\mathrm{CO}$ pressure.[2] They tentatively assigned this band to $\mathrm{CO}$ adsorbed on $\mathrm{Mg}^{2+}{ }_{3 \mathrm{C}}$ species (corners). A shoulder around $2185 \mathrm{~cm}^{-1}$ was detected with all $\mathrm{MgO}$ catalysts, however the band at $2202 \mathrm{~cm}^{-1}$ was observed only for C-, SG-, and MW-MgO (for example see inset in Fig. 1B).

In summary, the spectra presented in Fig. 1 are consistent with nano-structured $\mathrm{MgO}$ that exposes coordinatively unsaturated $\mathrm{Mg}^{2+}$ sites in fivefold, fourfold, and threefold coordinations at the surface. The fourfold-coordinated Mg cations comprise edges at monoatomic as well as multi-atomic steps.

Fig. 2 presents $\mathrm{CO}$ adsorption isotherms determined by plotting the integrated area of the entire $v_{\mathrm{CO}}$ band as a function of the $\mathrm{CO}$ equilibrium pressure at $77 \mathrm{~K}$. The differences in the maximum integrated area reflect both the surface area and surface nanostructure of the differently prepared $\mathrm{MgO}$ catalysts. Assuming that the 'knee' in each isotherm (Fig. 2A) corresponds to monolayer coverage, i.e. $\theta=1$, the $\mathrm{y}$-axis on each isotherm may be replaced by surface coverage, $\theta$ (Fig. 2B). In this manner, the equilibrium pressure of $\mathrm{CO}$ required to achieve a specific surface coverage was determined. Since, as established by Fig. 1B, the coordination of adsorbed $\mathrm{CO}$ is dependent on surface coverage, this procedure allows a more reliable comparison of the differently prepared $\mathrm{MgO}$ catalysts.

In Fig. 3 the spectra of adsorbed $\mathrm{CO}$ at $\theta=0.15$ are compared for all catalysts. At such a low coverage we expect that coupling effects between neighboring $\mathrm{CO}$ molecules are negligible. 
The difference in the total peak area follows the trend of the specific surface area (for specific surface areas determined by nitrogen adsorption at $77 \mathrm{~K}$ see the numbers in brackets in the legend of Fig. 3). For example, S-MgO exhibits the lowest total integrated intensity and has the lowest surface area of only $11 \mathrm{~m}^{2} / \mathrm{g}$, whereas $\mathrm{MW}-\mathrm{MgO}$, which exhibits the largest intensity, has the highest surface area of $111 \mathrm{~m}^{2} / \mathrm{g}$ indicating that the overall intensity is not strongly affected by the relative abundance of different $\mathrm{Mg}^{2+}$ sites exposed at the catalyst surface, i.e., the extinction coefficients of $\mathrm{CO}$ adsorbed on different $\mathrm{Mg}^{2+}$ sites seem to be similar.
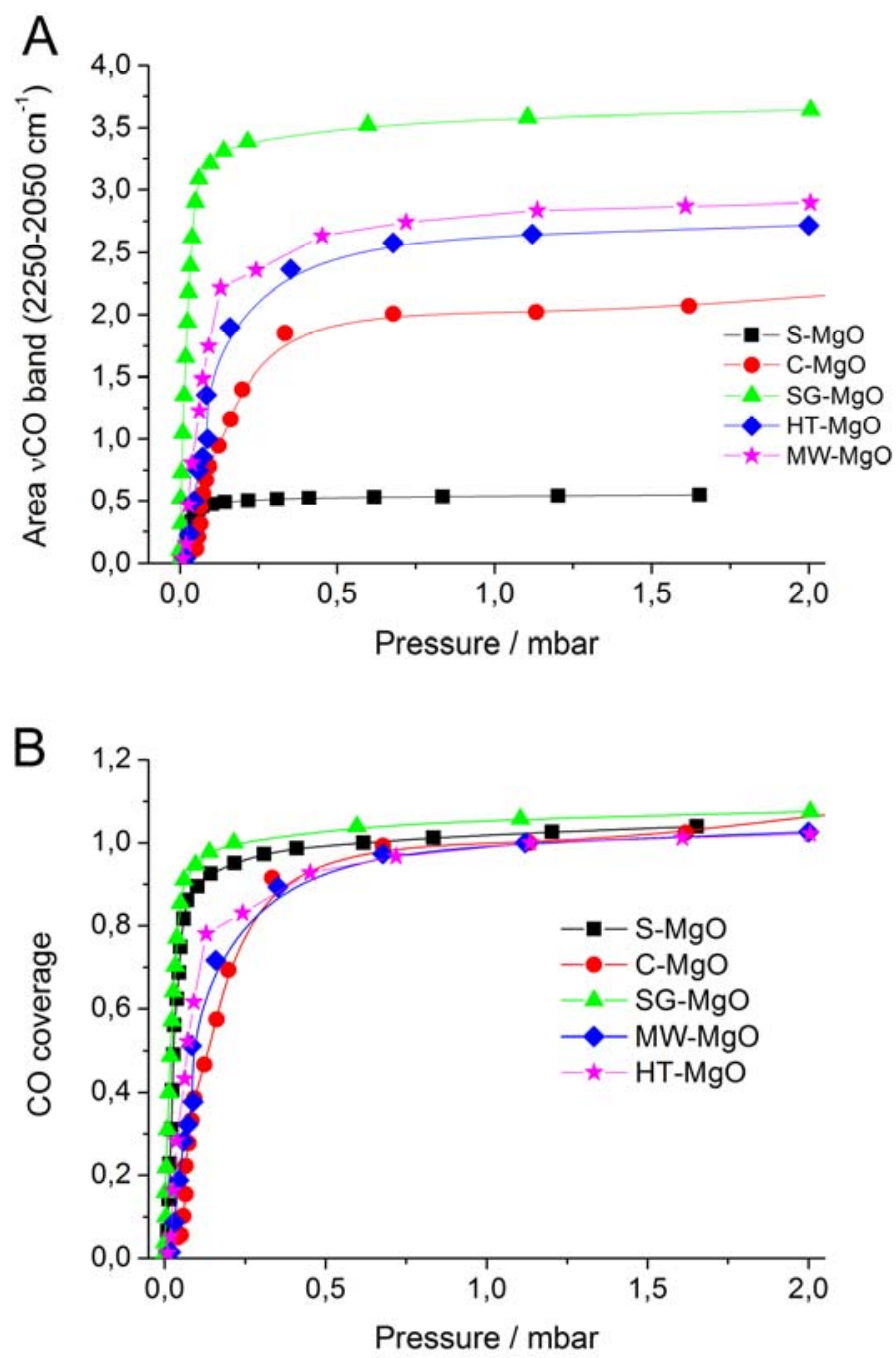

Fig. 2. Integrated area of the peaks of adsorbed $\mathrm{CO}$ as a function of the equilibrium $\mathrm{CO}$ pressure at $77 \mathrm{~K}$ (A) and the derived adsorption isotherms (B). The integrated area was determined using spectra normalized with respect to the mass of the wafer. 
The $\mathrm{MgO}$ catalyst prepared by smoke synthesis, $\mathrm{S}-\mathrm{MgO}$, exhibits the simplest spectrum, which is dominated by a signal at $2156 \mathrm{~cm}^{-1}$ that is associated with $\mathrm{Mg}^{2+} 5 \mathrm{C}$ terrace sites. A weak shoulder located at $2164 \mathrm{~cm}^{-1}$ is attributed to $\mathrm{Mg}^{2+}{ }_{4 \mathrm{C}}$ centres located at cubelet edges and/or multi-atomic step defects. The spectrum of $\mathrm{CO}$ adsorbed on $\mathrm{C}-\mathrm{MgO}$, exhibits generally higher intensity and is dominated by terrace sites $\left(2156 \mathrm{~cm}^{-1}\right)$, however the relative contribution of features associated with mono-atomic steps $\left(2146 \mathrm{~cm}^{-1}\right)$ is enhanced compared to $\mathrm{S}-\mathrm{MgO}$. Sol-gel prepared $\mathrm{MgO}$, SG-MgO, exhibits more terrace sites and mono-atomic steps, while the contribution from edges at multi-atomic steps $\left(2164 \mathrm{~cm}^{-1}\right)$ is similar to that of C-MgO. Hydrothermally treated $\mathrm{MgO}$, $\mathrm{HT}-\mathrm{MgO}$, features a major contribution from terrace sites $\left(2156 \mathrm{~cm}^{-1}\right)$ with a visible shoulder located at $2164 \mathrm{~cm}^{-1}$ due to edge sites at multi-atomic step defects. The contribution from mono-atomic step defects is reduced relative to both C$\mathrm{MgO}$ and SG-MgO. Finally, MgO prepared by hydrothermal microwave post-treatment, MW$\mathrm{MgO}$, exhibits a rather broad band with a maximum located at $2156 \mathrm{~cm}^{-1}$ indicating the predominance of terrace sites. However, due to the width of the band the presence of signals associated with edge sites and mono-atomic step defects cannot be excluded. Indeed, inspection of the associated TEM image of MW-MgO (Fig. 4) indicates that edge sites and mono-atomic steps are indeed present.

In summary, the differently prepared and freshly calcined magnesium oxides differ in the total concentration of coordinatively unsaturated $\mathrm{Mg}^{2+}$ surface sites at the surface. The total number of cationic sites probed by $\mathrm{CO}$ adsorption at $\theta=0.15$ displays the same trend as the total surface area determined by nitrogen adsorption. More important, the relative abundance of the different types of sites differs. $\mathrm{S}-\mathrm{MgO}$, for instance, shows no mono-atomic steps, while the concentration of the latter seems to be the highest on $\mathrm{MW}-\mathrm{MgO}$. 


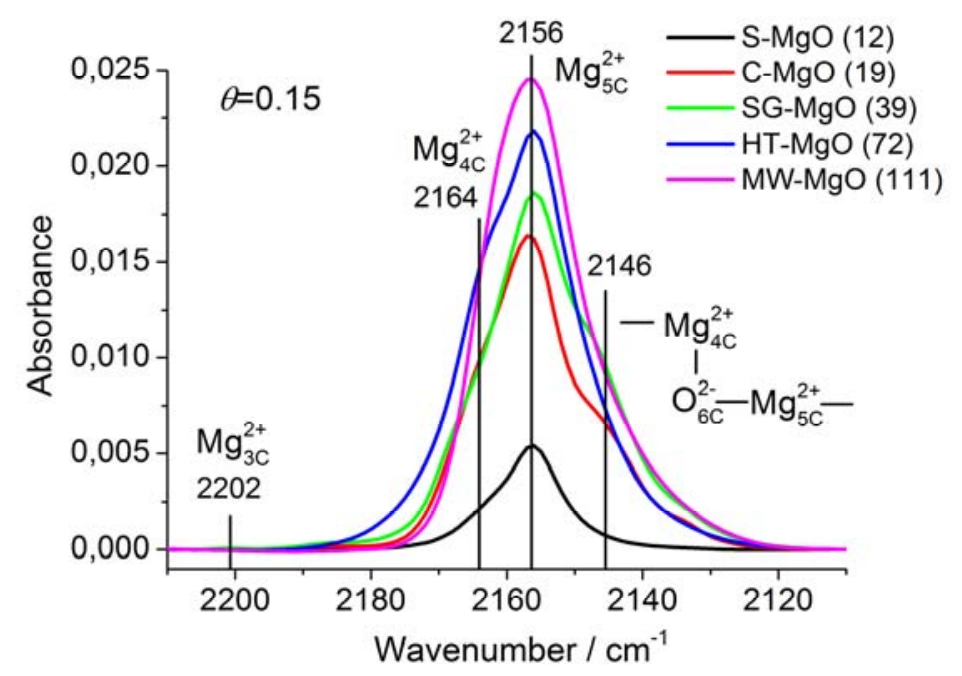

Fig. 3. Spectra of $\mathrm{CO}$ adsorbed on $\mathrm{MgO}$ at $\mathrm{T}=77 \mathrm{~K}$ at a coverage of $\theta=0.15$. The numbers in brackets in the legend correspond to the specific surface areas of the catalysts in $\mathrm{m}^{2} \mathrm{~g}^{-1}$.

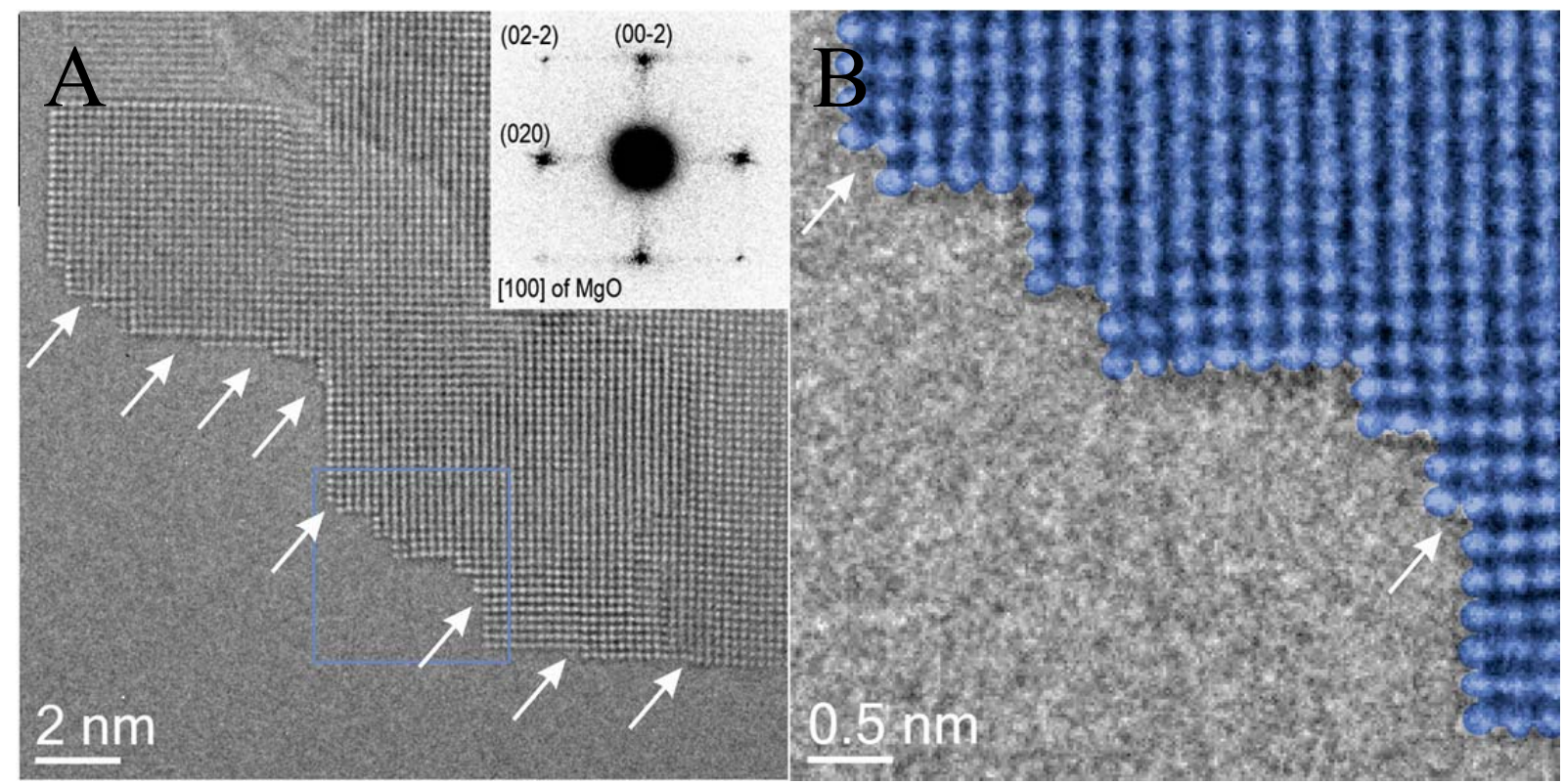

Fig. 4. High resolution TEM images of $\mathrm{MW}-\mathrm{MgO}$ viewed along [100]. The inset in (A) shows a power spectrum, which allows to identify the orientation of the $\mathrm{MgO}$ crystal. (B) represents a higher magnified micrograph of (A) taken at the marked region of interest. The mono-atomic steps at the surface are clearly visible and marked by arrows.

\subsubsection{Methane adsorption}

The IR spectrum of the free $\mathrm{CH}_{4}$ molecule is characterized by the triply degenerate antisymmetric stretching mode $v_{3}$ at $3020 \mathrm{~cm}^{-1}$ and the twofold degenerate $\mathrm{H}-\mathrm{C}-\mathrm{H}$ 
deformation mode $v_{4}$ at $1306 \mathrm{~cm}^{-1}$.[17-19] The infrared spectrum of $\mathrm{CH}_{4}$ adsorbed at $77 \mathrm{~K}$ on C-MgO (Fig. 5, red line) shows bands at 3003, 2896, and $2827 \mathrm{~cm}^{-1}$ in the region of C-H stretching vibrations and a band at $1304 \mathrm{~cm}^{-1}$ in the region of deformation vibrations. The shift of $17 \mathrm{~cm}^{-1}$ compared to the gas phase $v_{3}$ mode and the appearance of a band at $2896 \mathrm{~cm}^{-1}$ due to the infrared-forbidden $v_{1}$ stretching vibration (Raman band of the free molecule at $\left.2914 \mathrm{~cm}^{-1}\right)[17]$ indicate that the methane is considerably polarized upon adsorption, which goes along with a reduction of the $T_{d}$ symmetry of the molecule. However, the $v_{4}$ deformation mode located at $1304 \mathrm{~cm}^{-1}$ is practically not shifted with respect to gas phase $\mathrm{CH}_{4}$. The $v_{2}$ mode (Raman band of the free molecule at $1526 \mathrm{~cm}^{-1}$ ) remains IR inactive. The band located at $2827 \mathrm{~cm}^{-1}$ (Fig. 5) may be assigned to a combination mode of $v_{4}$ and $v_{2}$. The observed bands are attributed to methane interacting with coordinatively unsaturated sites at the surface of C-MgO. Methane adsorption on regular $\{100\} \mathrm{MgO}$ terrace sites has been excluded based on theoretical and experimental studies.[17] It is generally assumed that methane adsorbs on $\mathrm{MgO}$ in either monodentate coordination on basic Lewis sites (coordinatively unsaturated $\mathrm{O}^{2-}$ at corners only), or in polydentate coordination on $\mathrm{Mg}^{2+}-\mathrm{O}^{2-}$ Lewis acid/base pairs at edges (Scheme 1).[17, 18] DFT calculations support the hypothesis that methane prefers polydentate coordination at edges.[17] Li et al. observed two $v_{1}$ C-H stretching modes located at 2900 and $2890 \mathrm{~cm}^{-1}$, respectively, which were attributed to methane strongly adsorbed on two different acid-base pairs on the surface of $\mathrm{MgO}$.[18] In their study, they found only one $v_{3}$ mode, which shows a considerable red-shift to $3000 \mathrm{~cm}^{-1}$, that was attributed to adsorption on acidbase pairs. Furthermore, methane weakly adsorbed on coordinatively unsaturated oxygen anions at corners was assumed to result in a smaller red-shift of the $v_{3}$ mode to about 3008 $\mathrm{cm}^{-1}$ without significant reduction of the symmetry of the molecule and, consequently, the absence of the IR-forbidden $v_{1}$ mode.[18] We noticed that for the $\mathrm{MgO}$ catalysts considered here a band at $2890 \mathrm{~cm}^{-1}$ was not observed unless a high pressure (ca. $>700 \mathrm{~Pa}$ ) of $\mathrm{CH}_{4}$ was 
admitted. At such equilibrium pressures, signals associated with gas phase $\mathrm{CH}_{4}$ are already significant indicating that the corresponding surface species is rather weakly adsorbed. Irrespective of the conflicting assignments in the literature, broadness and shape of the observed $v_{3}$ and $v_{1}$ C-H stretching bands indicate that various different coordination complexes of adsorbed methane are present on the surface of $\mathrm{C}-\mathrm{MgO}$. This deduction is entirely consistent with the different $\mathrm{Mg}^{2+}$ environments revealed by IR spectroscopy of adsorbed CO (Figs. 1 and 3).

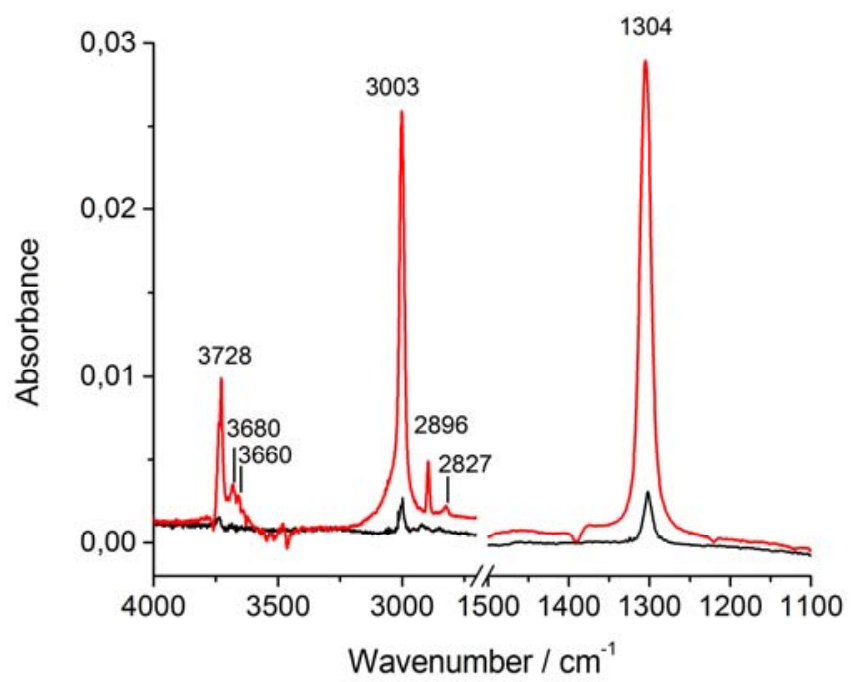

Fig. 5. Adsorption of ca. $10 \mathrm{~Pa} \mathrm{CH}_{4}$ at $\mathrm{T}=77 \mathrm{~K}$ on pretreated $\mathrm{C}-\mathrm{MgO}$ (red line) and after preadsorption of $200 \mathrm{~Pa} \mathrm{CO}$ (black line). 


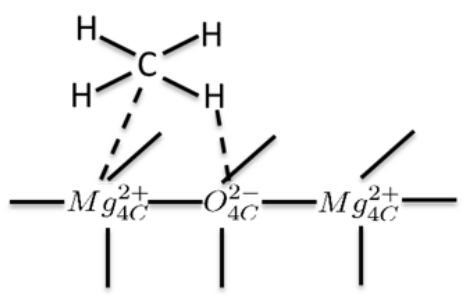

Edges

Lewis acid/base pair

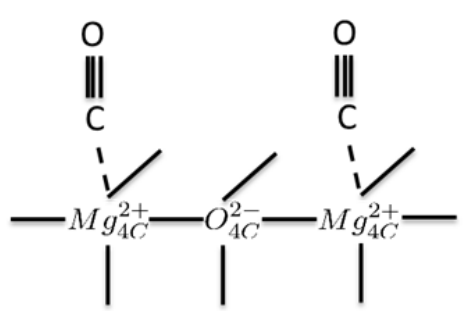

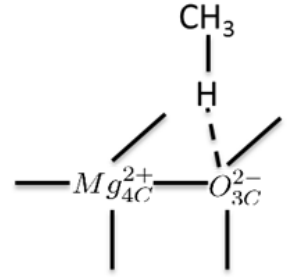

Corners

Lewis base

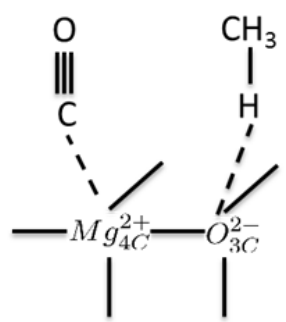

Scheme 1. Coordination of methane and $\mathrm{CO}$ at the $\mathrm{MgO}$ surface.

The spectrum of adsorbed methane shows additional bands in the region of $\mathrm{O}-\mathrm{H}$ stretching vibrations at 3728,3680 , and $3660 \mathrm{~cm}^{-1}$ (Fig. 5, red line). The wavenumbers are characteristic of $\mathrm{Mg}-\mathrm{OH}$ species in different coordination.[20] Interestingly, these bands that have to the best of our knowledge not yet been reported in the literature for methane adsorption on $\mathrm{MgO}$, disappear along with the other methane bands upon evacuation at $77 \mathrm{~K}$ (Supporting information, Fig. S1). This indicates that they are due to a very weakly bound surface species. The $v_{\mathrm{OH}}$ signal could be caused by dissociative adsorption of methane, whereby new hydroxyl and methyl groups are formed on neighboring $\mathrm{O}^{2-}$ and $\mathrm{Mg}^{2+}$ sites, respectively. However the fact that the signals were completely removed by evacuation at $77 \mathrm{~K}$ (Fig. S1), render this explanation rather unlikely. Therefore, these features are tentatively assigned to hydrogenbonded moieties (-Mg-O--- $\left.\mathrm{H}-\mathrm{CH}_{3}\right)$ present in di-hapto methane adsorption complexes. Apparently, adsorption sites on $\mathrm{MgO}$ are capable of polarizing the $\mathrm{C}-\mathrm{H}$ bonds in such a way that not only IR inactive vibrations of $\mathrm{CH}_{4}$, but also discrete $v_{\mathrm{OH}}$ signals due to hydrogen atoms of methane, which interact with $\mathrm{O}^{2-}$ sites at the $\mathrm{MgO}$ surface, become visible. The interaction geometry of methane with acid-base pair sites proposed by Li et al.[18] certainly 
implies an agostic interaction between $\mathrm{C}-\mathrm{H}$ and the acid-base pair, which could then lead to a polarization of the adsorbed methane possibly resulting in an enhanced interaction between the neighboring basic $\mathrm{O}^{2-}$ and the methyl hydrogen. The fact that the -Mg-O--- $\mathrm{H}-\mathrm{CH}_{3}$ features are not observed in the co-adsorption experiments, where $\mathrm{Mg}^{2+}$ centres are saturated by $\mathrm{CO}$ (Fig. 5, black line), indicates that they must be associated with acid-base pair sites only, because CO blocks these sites (Scheme 1 and discussion below).

Reference experiments, including adsorption of water, methanol, and hydrogen at $77 \mathrm{~K}$ (results not shown) revealed that impurities in methane are excluded as origin of the $\mathrm{O}-\mathrm{H}$ stretching vibrations observed during methane adsorption. To verify with certainty that the observed $v_{\mathrm{OH}}$ signal is indeed caused by the polarization of a $\mathrm{C}-\mathrm{H}$ bond, the adsorption of deuterated methane $\left(\mathrm{CD}_{4}\right)$ was studied by FTIR spectroscopy. Fig. 6 represents the infrared spectrum of $\mathrm{CD}_{4}$ adsorbed on $\mathrm{C}-\mathrm{MgO}$ at $77 \mathrm{~K}$ applying an equilibrium pressure of $100 \mathrm{~Pa}$ and after evacuation. $\mathrm{CH}_{4}$ adsorption at the same pressure is shown in Figure S1. The antisymmetric stretching mode $v_{3}$ of free $\mathrm{CD}_{4}$ is red shifted from $2259 \mathrm{~cm}^{-1}$ to $2248 \mathrm{~cm}^{-1}$ and the deformation mode $v_{4}$ is shifted from $996 \mathrm{~cm}^{-1}$ to $992 \mathrm{~cm}^{-1}$ indicating polarization of the molecule like in case of $\mathrm{CH}_{4}$. At least three new bands appear at 3234, 3086, and $2927 \mathrm{~cm}^{-1}$ (OD stretching region enlarged in Fig. 6B). The intensity of these bands increases with increasing $\mathrm{CD}_{4}$ equilibrium pressure and decreases upon evacuation. In analogy to the $\mathrm{CH}_{4}$ adsorption, we tentatively assign these bands to D-bonded OD moieties (-Mg-O---D-CD $\mathrm{CD}_{3}$ of $\mathrm{CD}_{4}$ adsorbed at different sites. 

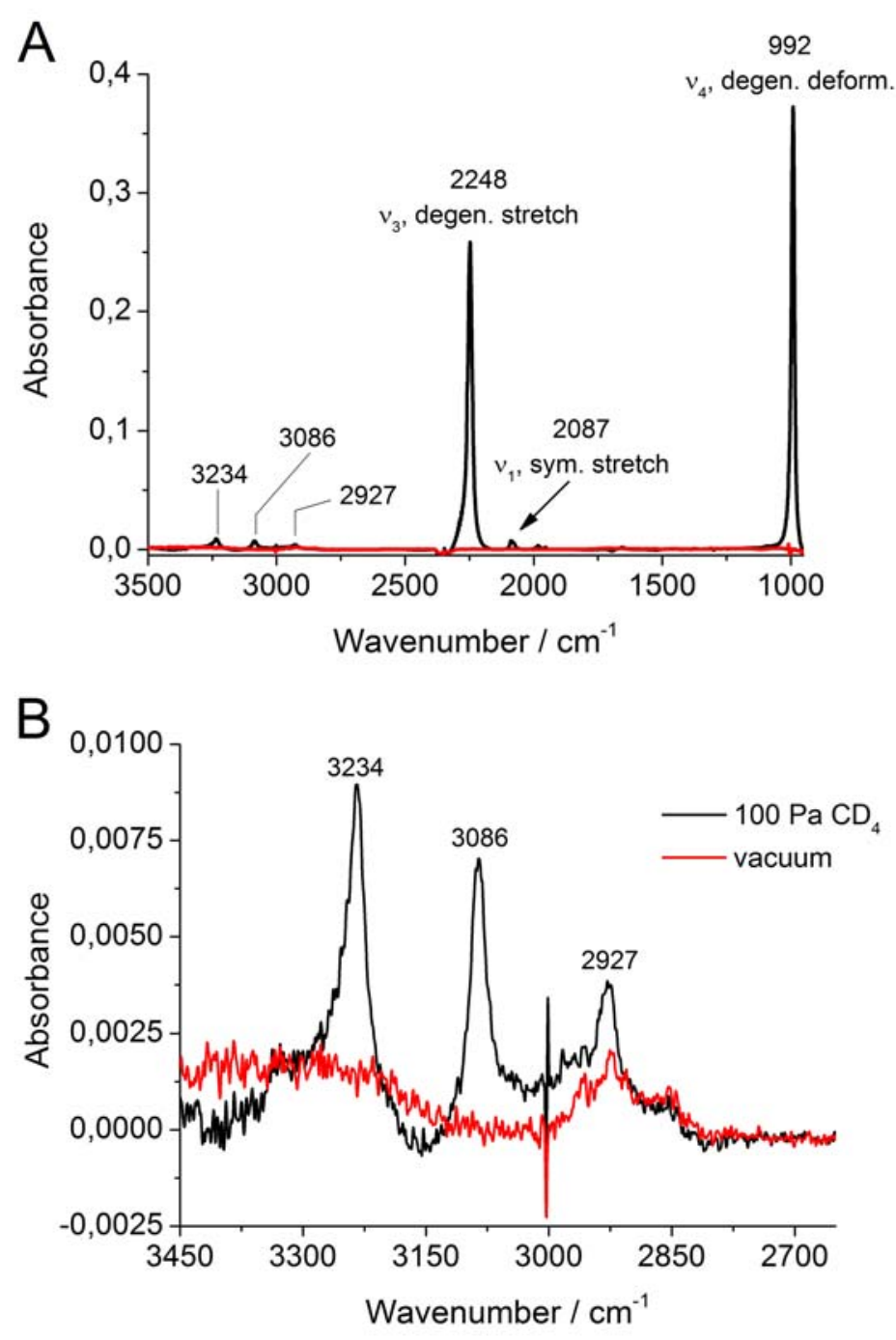

Fig. 6. (A) Adsorption of $100 \mathrm{~Pa} \mathrm{CD}_{4}$ at $\mathrm{T}=77 \mathrm{~K}$ at the surface of $\mathrm{C}-\mathrm{MgO}$ dehydroxylated at $1073 \mathrm{~K}$. (B) Enlarged representation of the spectra in the range of O-D stretching vibrations. Black line: adsorption of $100 \mathrm{PaCD}_{4}$, red line: after evacuation up to $5 \cdot 10^{-4} \mathrm{~Pa}$.

The absence of carbonite bands (Fig. 1A) indicates that carbon monoxide interacts at $77 \mathrm{~K}$ only with acidic sites $\left(\mathrm{Mg}^{2+}\right)$ on the surface of $\mathrm{MgO}$. A decrease in the integrated absorbance of infrared bands of adsorbed methane in the presence of adsorbed $\mathrm{CO}$ compared to that in the absence of $\mathrm{CO}$ (Fig. 5, black line) gives an indication of the number of Lewis acid/base pairs available for methane adsorption. As discussed above, methane adsorbs in absence of CO in a di-hapto coordination on $\mathrm{Mg}^{2+}-\mathrm{O}^{2-}$ acid-base pairs at edges and in a mono-hapto coordination on basic $\mathrm{O}^{2-}$ adsorption sites at corners. In co-adsorption measurements, where pre-adsorbed CO comprises a saturated overlayer, the band at $3003 \mathrm{~cm}^{-1}$ becomes less 
dominant (Fig. 5, black line). Clearly, this is due to the fact that the more basic CO molecule has occupied cationic sites, leaving only basic $\mathrm{O}^{2-}$ sites (corners) for methane adsorption. As shown in Fig. 5, also the intensity of the $\delta_{\mathrm{CH}}$ band $v_{4}$ located at $1304 \mathrm{~cm}^{-1}$ is severely diminished in the presence of an excess of $\mathrm{CO}(200 \mathrm{~Pa}, \theta \geq 1)$ due to the same reason. Thus, discrimination between cationic (acid) and anionic (basic) adsorption sites is possible by coadsorption of $\mathrm{CO}$ and $\mathrm{CH}_{4}$. By comparing the integrated area of the $v_{4}$ band in both the absence and presence of $\mathrm{CO}$, the relative abundance of acid-base pair sites (edges) in the different $\mathrm{MgO}$ catalysts can be analyzed (Fig. 7). The height of the green bars in Figure 7 is a measure of the total number of adsorption sites of methane (di-hapto adsorption at $\mathrm{Mg}^{2+}-\mathrm{O}^{2-}$ acid-base pair sites at edges plus mono-hapto adsorption at basic $\mathrm{O}^{2-}$ sites (corners)). The blue bars indicate the number of the basic $\mathrm{O}^{2-}$ adsorption sites at corners only. The numbers presented on top of the green bars indicate the relative content of acid-base pair sites (edges) in percentage. From these numbers it becomes clear that the acid-base pairs at the edges are the predominant adsorption sites for all $\mathrm{MgO}$ preparations. The relative abundance of edges

versus corners decreases in the following order: $\mathrm{S}-\mathrm{MgO} \approx \mathrm{C}-\mathrm{MgO}>\mathrm{SG}-\mathrm{MgO}>\mathrm{MW}-$ $\mathrm{MgO}>\mathrm{HT}-\mathrm{MgO}$.

\subsubsection{Used catalysts}

In order to determine changes occurring at the catalyst surface during OCM we applied the methodology previously established for characterizing fresh catalysts to catalysts after several hundred hours time on stream (TOS) in the OCM reaction. 


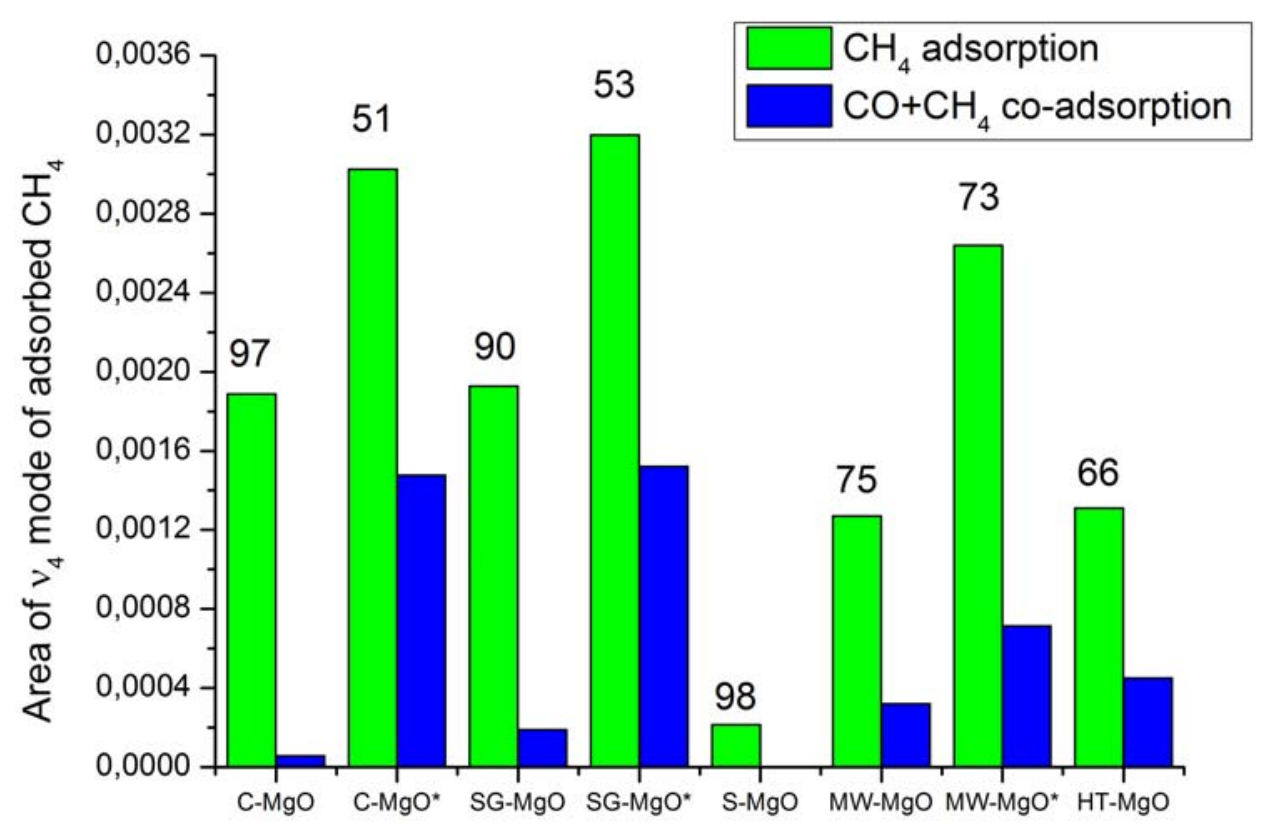

Fig. 7. Integrated areas of the $v_{4}$ mode of adsorbed $\mathrm{CH}_{4}\left(\mathrm{p}_{\mathrm{eq}}=100 \mathrm{~Pa}\right)$ (green bars), and of adsorbed $\mathrm{CH}_{4}\left(\mathrm{p}_{\mathrm{eq}}=100 \mathrm{~Pa}\right)$ after the surface has been pre-saturated with $\mathrm{CO}\left(\mathrm{p}_{\mathrm{eq}}=200 \mathrm{~Pa}\right.$, i.e. $\theta=1$ ), (blue bars) at $\mathrm{T}=77 \mathrm{~K}$ on fresh and used $\mathrm{MgO}$. The stars indicate that the catalyst has been used in oxidative coupling of methane under the following reaction conditions: $\mathrm{CH}_{4} / \mathrm{O}_{2} / \mathrm{N}_{2}=3 / 1 / 1, \mathrm{~W} / \mathrm{F}=0.15 \mathrm{~g} \cdot \mathrm{s} \cdot \mathrm{ml}^{-1}, \mathrm{~T}=1073 \mathrm{~K}$, TOS $=300 \mathrm{~h}$. The numbers presented on top of the green bars indicate the relative content of acid-base pair sites (edges) in percentage.

\subsubsection{CO adsorption}

Fig. 8 exemplarily shows a comparison of infrared spectra of $\mathrm{CO}$ adsorbed on $\mathrm{C}-\mathrm{MgO}$ before and after $300 \mathrm{~h}$ TOS in OCM at $1073 \mathrm{~K}$. Both spectra have been recorded at a CO coverage $\theta=0.08$. The simplicity of the spectrum of $\mathrm{CO}$ adsorbed on used $\mathrm{C}-\mathrm{MgO}$ is striking and indicates that the catalyst surface was significantly modified under OCM reaction conditions. The mono-atomic steps $\left(2146 \mathrm{~cm}^{-1}\right)$ are practically missing. Features located at 2157 and $2164 \mathrm{~cm}^{-1}$ assigned to $\mathrm{CO}$ adsorbed on terrace and edge sites, respectively, are present, but significantly attenuated due to the reduction of the specific surface area from $19 \mathrm{~m}^{2} / \mathrm{g}$ in the fresh catalyst to $8 \mathrm{~m}^{2} / \mathrm{g}$ in the spent one. The most intense feature is observed at $2169 \mathrm{~cm}^{-1}$, which corresponds to $\mathrm{CO}$ bound to multi-atomic step sites (edges). Two new weak bands for $\mathrm{CO}$ adsorbed at corners appear in the range between 2190 and $2210 \mathrm{~cm}^{-1}$. Fig. 8 clearly 
demonstrates that $\mathrm{OCM}$ reaction conditions transform $\mathrm{MgO}$ surfaces rich in mono-atomic step sites into surfaces dominated by multi-atomic steps and corners.

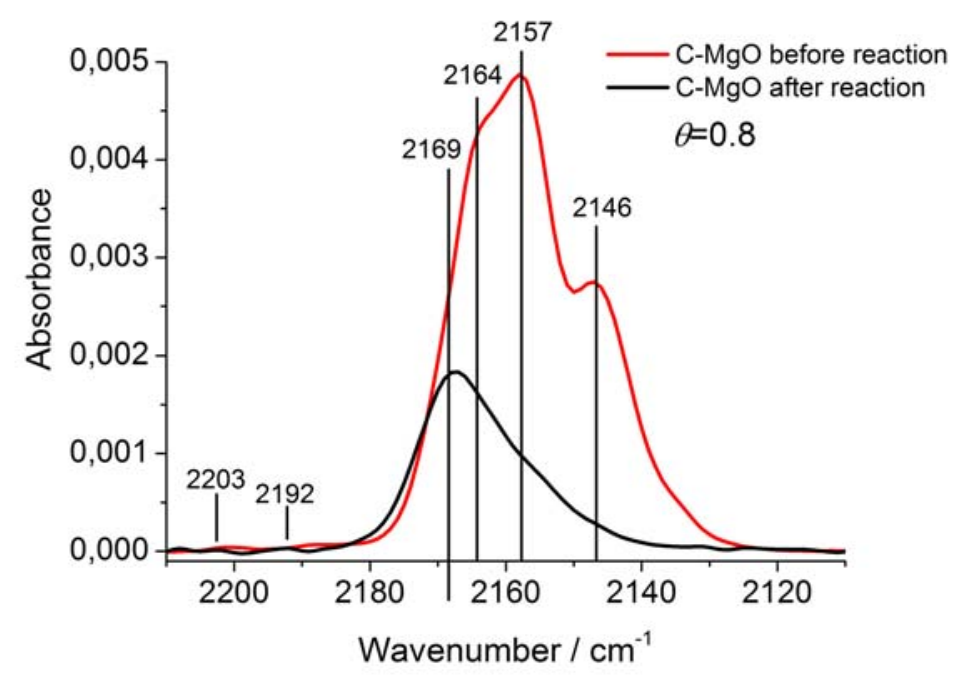

Fig. 8. Spectra of $\mathrm{CO}$ adsorbed at $\mathrm{T}=77 \mathrm{~K}$ at $\theta=0.08$ on $\mathrm{C}-\mathrm{MgO}$ after calcination (red line) and after application in oxidative coupling of methane (black line) under the following reaction conditions: $\mathrm{CH}_{4} / \mathrm{O}_{2} / \mathrm{N}_{2}=3 / 1 / 1, \mathrm{~W} / \mathrm{F}=0.15 \mathrm{~g} \cdot \mathrm{s} \cdot \mathrm{ml}^{-1}, \mathrm{~T}=1073 \mathrm{~K}$, TOS $=300 \mathrm{~h}$.

The used catalysts generally adsorb more methane than the fresh ones (compare the green bars in Fig. 7). The reduction of the total specific surface area is apparently compensated by an increase in the number of defects where methane can be adsorbed and a decrease in the fraction of terrace sites where methane does not adsorb. The fraction of acid-base pairs decreases drastically for C-MgO and SG-MgO from about 90 to about 50\%, but stays almost unchanged at about $70 \%$ for $\mathrm{MW}-\mathrm{MgO}$. Fresh $\mathrm{C}-\mathrm{MgO}$ and $\mathrm{SG}-\mathrm{MgO}$ catalysts exhibit an almost ideal cubic nanostructure with well-defined structural defects present on their $\{100\}$ surfaces (see Fig. 1C-E in [1]). During the reaction, sintering of the particle causes a loss of the cubic structure and the formation of a highly defective structure, which explains the increase of corner sites, i.e. the decrease in the fraction of acid-base pairs at edges. In the case of $\mathrm{MW}-\mathrm{MgO}$, the structure of the fresh catalyst is already highly defective. Sintering during the OCM reaction leads to a decrease in the surface area and an increase in the mean particle 
size as determined by $\mathrm{XRD}$, but the relative concentration of corners and acid-base pairs (edges) does not change.

In summary, the most striking differences between fresh and used catalysts are (i) the disappearance of mono-atomic steps, (ii) an increase in the fraction of $\mathrm{O}^{2-}$ corners sites, and (iii) in some cases a reduction of the relative amount of acid-base pairs (edges) indicating that substantial changes in the nature of morphological defects occur during catalysis.

\subsection{Photoluminescence (PL) spectroscopy}

Properties of morphological defects in alkaline earth oxides are of interest in terms of their catalytic properties. Differences in the coordination number of surface ions modify their Madelung potential and result in changes in the local acceptor-donor (acid-base) behavior. Garrone et al. demonstrated based on the Levine-Mark model[21] that excitation energies in the UV-vis range reflect the local coordination number (and the Madelung potential, respectively) of surface ions of alkaline earth oxides.[22] In other words, the presence of morphological defects on the surface of alkaline earth oxides is responsible for the presence of intrinsic discrete energy levels within the band-gap, i.e. local acceptor-donor pairs, which can be probed by UV light. Hence, $\mathrm{MgO}$ was intensively investigated by diffuse reflectance spectroscopy. General consensus has been reached concerning the assignment of the absorption bands to the corresponding structural defects.[22] The UV-Vis spectrum of C$\mathrm{MgO}$ reveals typical bands at $218 \mathrm{~nm}(5.69 \mathrm{eV})$, and $266 \mathrm{~nm}(4.66 \mathrm{eV})$ that are assigned to transitions associated with 4-fold and 3-fold coordinated oxygen atoms at edges and corners, respectively (Fig. S2). Light emission has also been observed for $\mathrm{MgO}$ powders in the UV and blue visible range after excitation with photons [23] or via electron injection from a scanning tunneling microscope tip.[24] Photoluminescence (PL) spectroscopy is, therefore, complementarily used to sensitively probe defects and low-coordinated edge or corner sites (structural defects).[25] However, the interpretation of the emission spectra is not 
straightforward since several recombination and energy transfer phenomena may occur after the excitation. $[6,25,26]$ The emission spectra depend on the energy of the light used for excitation. Generally, sets of excitation-emission $\left(\lambda_{\mathrm{exc}}, \lambda_{\mathrm{em}}\right)$ wavelengths are provided in the literature. These couples are identified experimentally by recording emission spectra (recording the spectrum of the emitted light at a fixed excitation wavelength) and excitation spectra (changing the excitation wavelength and recording the emission at a fixed wavelength). In order to gain an improved spectral resolution and to achieve a clear determination of the excitation-emission sets, 2D photoluminescence (2D PL) spectroscopy was performed in the present study. Fig. 9 presents the 2D PL patterns of fresh (A) and used (B) $\mathrm{C}-\mathrm{MgO}$ recorded in dynamic vacuum after annealing at $1073 \mathrm{~K}$ in vacuum for 6 hours. The conjugated excitation-emission $\left(\lambda_{\mathrm{exc}}-\lambda_{\mathrm{em}}\right)$ wavelengths are summarized in Table 1 and compared with the results of a theoretical study.[6] The patterns of S-, and SG-MgO before and after catalysis are shown in the supporting information (Figs. S3-S6).

Generally, five different species have been identified previously by one-dimensional PL spectroscopy at the surface of dehydroxylated $\mathrm{MgO}$ powders and assigned based on timedependent DFT calculations.[6] Fourfold coordinated oxygen anions $\left(\mathrm{O}^{2-}{ }_{4 \mathrm{c}}\right)$ at edges give rise to an excitation-emission couple at $(240,380) \mathrm{nm}$. Two different species, namely 3-fold coordinated oxygen anions $\left(\mathrm{O}^{2-}{ }_{3 \mathrm{c}}\right)$ at corners, and $\mathrm{O}_{3 \mathrm{c}}^{2-}$ at kinks (corners are the crossing points between three extended edges, whereas a kink comprises at least one short edge, e.g., a kink is for example a corner at a mono-atomic step) together with $\mathrm{O}^{2-}{ }_{4 \mathrm{c}}$ close to corners and kinks are characterized by the same excitation-emission wavelengths at $(280,470) \mathrm{nm}$. The latter two species are distinguishable by different lifetimes. $\mathrm{O}^{2-}{ }_{3 \mathrm{c}}$ at corners together with $\mathrm{O}^{2-}{ }_{4 \mathrm{c}}$ close to $\mathrm{Mg}^{2+}$ 3c kinks are supposed to be responsible for an excitation-emission couple at $(320,530) \mathrm{nm}$. A couple at $(350,605) \mathrm{nm}$ is attributed to $\mathrm{O}^{2-}$ c at kinks. 

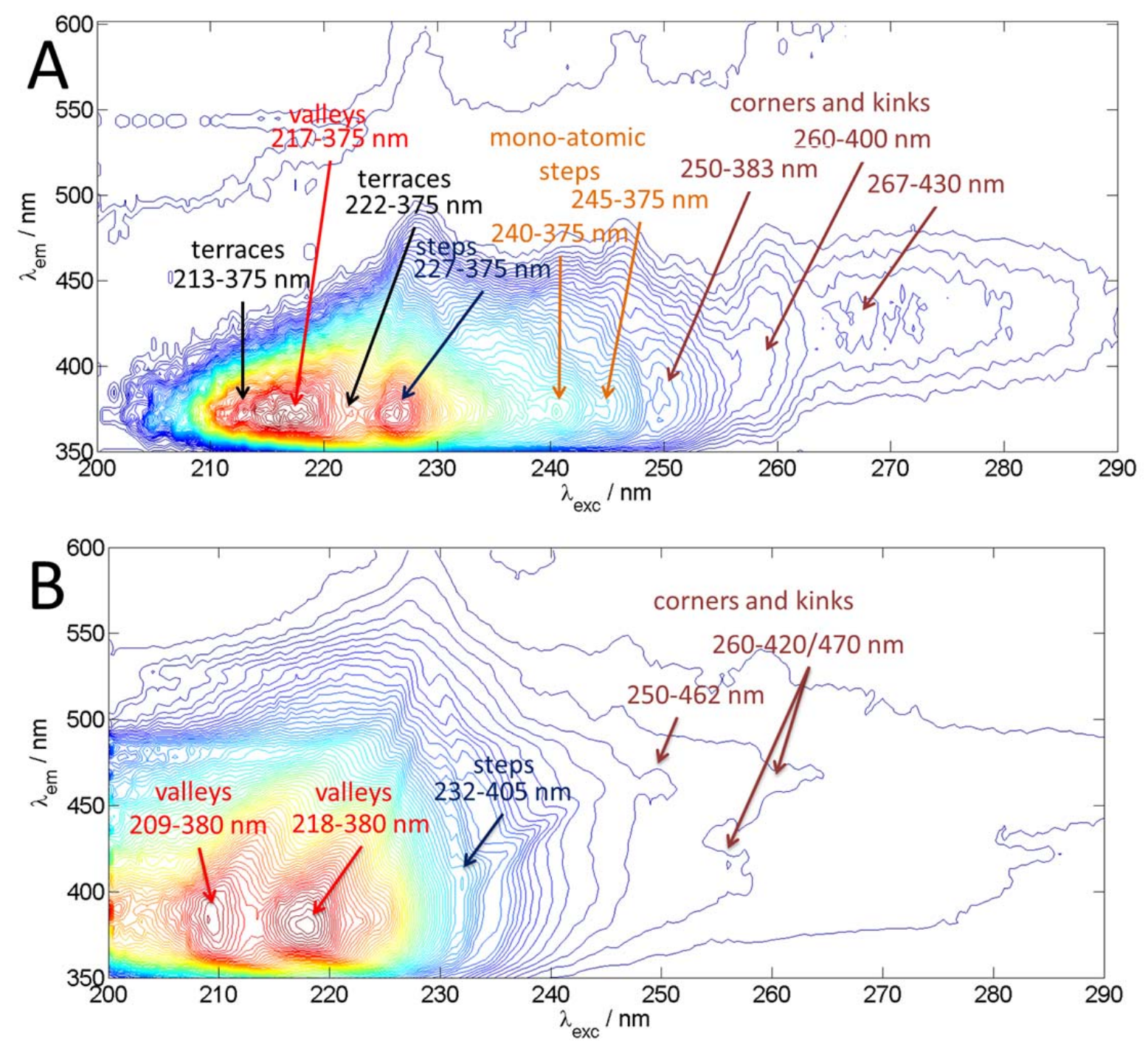

Fig. 9. 2D photoluminescence patterns of fresh (A) and used (B) C-MgO normalized with respect to the intensity. Excitation-emission couples are indicated by arrows.

Our experimental results are only in part compatible with the literature showing a single agreement in terms of the excitation-emission set at $(240,380) \mathrm{nm}$.[6] The 2D PL patterns of fresh $\mathrm{C}-\mathrm{MgO}$ reveal that for six different excitations in the range between 213 and $245 \mathrm{~nm}$, light is emitted exclusively at $375 \mathrm{~nm}$ irrespective of the energy of excitation. In addition, couples at $(260,400)$, and $(267,430) \mathrm{nm}$ are observed (Fig. 9 A, Table 1).

After extended time on stream in the OCM reaction, some features observed for the fresh catalyst disappear and some new features appear at higher emission wavelengths (Fig. 9 B, Table 1). The two most intense couples for fresh $\mathrm{MgO}$ at $(213,375) \mathrm{nm}$ and $(222,375) \mathrm{nm}$ 
vanish almost entirely. The couples at $(240,375) \mathrm{nm}$ and $(245,375) \mathrm{nm}$ disappear completely. New couples at $(250,462) \mathrm{nm}$ and $(260,465) \mathrm{nm}$ appear, which have not been reported before.

The observed excitation bands are in good agreement with the IR spectroscopic results (Fig. 8) and theoretical calculations by Chizallet et al. (Table 1).[6] The fresh $\mathrm{MgO}$ surface exhibits mainly terraces that contain localized morphological defects. Six-fold and five-fold coordinated oxygen anions at terraces are excited at 213 and $222 \mathrm{~nm}$, respectively, and emit light at $375 \mathrm{~nm}$ (Fig. 9 A, Table 1). The corresponding species are extinguished by using the catalyst in the OCM reaction. Due to sintering, the catalyst surface becomes highly defective and exhibits almost no wide terraces anymore. At the same time, excitation bands assigned to valleys and edges at 209, 218, and $232 \mathrm{~nm}$, respectively, become more intense (Fig. 9 B). In accordance with IR spectroscopy (Fig. 8), the features at 240 and $245 \mathrm{~nm}$ observed only in the fresh catalyst, but not in the used one, are assigned to mono-atomic steps that disappear under OCM conditions. The weak features at $260 \mathrm{~nm}$ in the fresh catalyst, and at $250 \mathrm{~nm}$ in used C$\mathrm{MgO}$ are attributed to corners and kinks, respectively, according to theoretical calculations (Table 1).[6] Charge transfer from the edges near the corners can occur,[5-7] which explains the slightly higher emission wavelength at $400 \mathrm{~nm}$.

The 2D PL patterns of S-MgO and SG-MgO (Figs. S3-S6) reflect the morphological differences between the different $\mathrm{MgO}$ catalysts. Features at $(216,378) \mathrm{nm}$ and $(220,378) \mathrm{nm}$ due to terrace sites are dominant in the patterns of $\mathrm{S}-\mathrm{MgO}$ in accordance with the almost ideal cubic morphology of the catalyst particles. The patterns of SG-MgO are more complex and signals at $(246,383) \mathrm{nm}$, and $(265,407) \mathrm{nm}$ that indicate the presence of mono-atomic steps and corners, respectively, appear more prominent due to the pronounced surface texturing of SG-MgO in agreement with the IR spectroscopic results (Fig. 3) and electron microscopy.[1] 
As aforementioned, the 2D PL spectra of nanostructured $\mathrm{MgO}$ exhibit several different excitation peaks, which are associated with the same emission energy at approximately 375 $\mathrm{nm}$. This peculiarity is tentatively attributed to charge transfer phenomena based on structural considerations. Fresh $\mathrm{C}-\mathrm{MgO}$ is terminated mainly by non-polar $\{100\}$ planes. Edges, corners, kinks, and other topological forms at the $\{100\}$ surface of $\mathrm{C}-\mathrm{MgO}$ can be regarded as localized structural defects. Since the neighborhood of all these defects is similar, charge transfer from different exited states into the same excited state, which is provided by the surrounding area of the defects, and from which the light is emitted, could occur. Accordingly, although different energy is required to excite the diverse structural defects (depending on their coordination number and configuration), the emitted light is of the same energy $(375 \mathrm{~nm})$ for most of them.

After several hundreds hours under OCM reaction condition, the $\mathrm{MgO}$ surface becomes highly defective and exposes higher index planes, thus, the electric dipole moment of the surface changes considerably and in this case, the relaxation process of excited ion pairs changes too. An increase in the emission wavelength can be observed that goes along with the supposed increase in the polarity of the planes. The species on the surface of the used catalyst that absorbs at about $230 \mathrm{~nm}$ emits light at $405 \mathrm{~nm}$, which corresponds to a shift of $0.25 \mathrm{eV}$ referred to $375 \mathrm{~nm}$ for the fresh catalyst. This shift could be explained by the reconstruction of $\{100\}$ planes into $\{110\}$ planes under reaction condition of OCM. Similarly, the shift of the emission for the excitation band at $250 \mathrm{~nm}$ from 375 to $462 \mathrm{~nm}(\Delta=0.6 \mathrm{eV})$ can be explained by transformation of $\{100\}$ planes into $\{111\}$ planes. The differences in the termination of differently prepared magnesium oxides $\mathrm{C}-\mathrm{MgO}, \mathrm{S}-\mathrm{MgO}$, and SG-MgO are, accordingly, also sensitively reflected in differing excitation-emission patterns (Figs. S3-S6).

In summary, the energy needed to excite an electronic transition in a species that belongs to a structural defect at the surface of $\mathrm{MgO}$ depends on the intrinsic electronic properties of this 
species, i.e., on the coordination number and the local topology.[6] Photoluminescence, i.e., the energy of the emitted light, however, seems to probe sensitively the dipolar moment of the microfacets where the corresponding defect is located. PL spectroscopy of fresh and used $\mathrm{MgO}$ catalysts documents, therefore, impressively the reconstruction of the $\mathrm{MgO}$ surface under OCM conditions.

\section{Table 1}

Excitation-emission couples experimentally observed for fresh and used $\mathrm{C}-\mathrm{MgO}$ in comparison with calculated components of excitation energy maxima.[6]

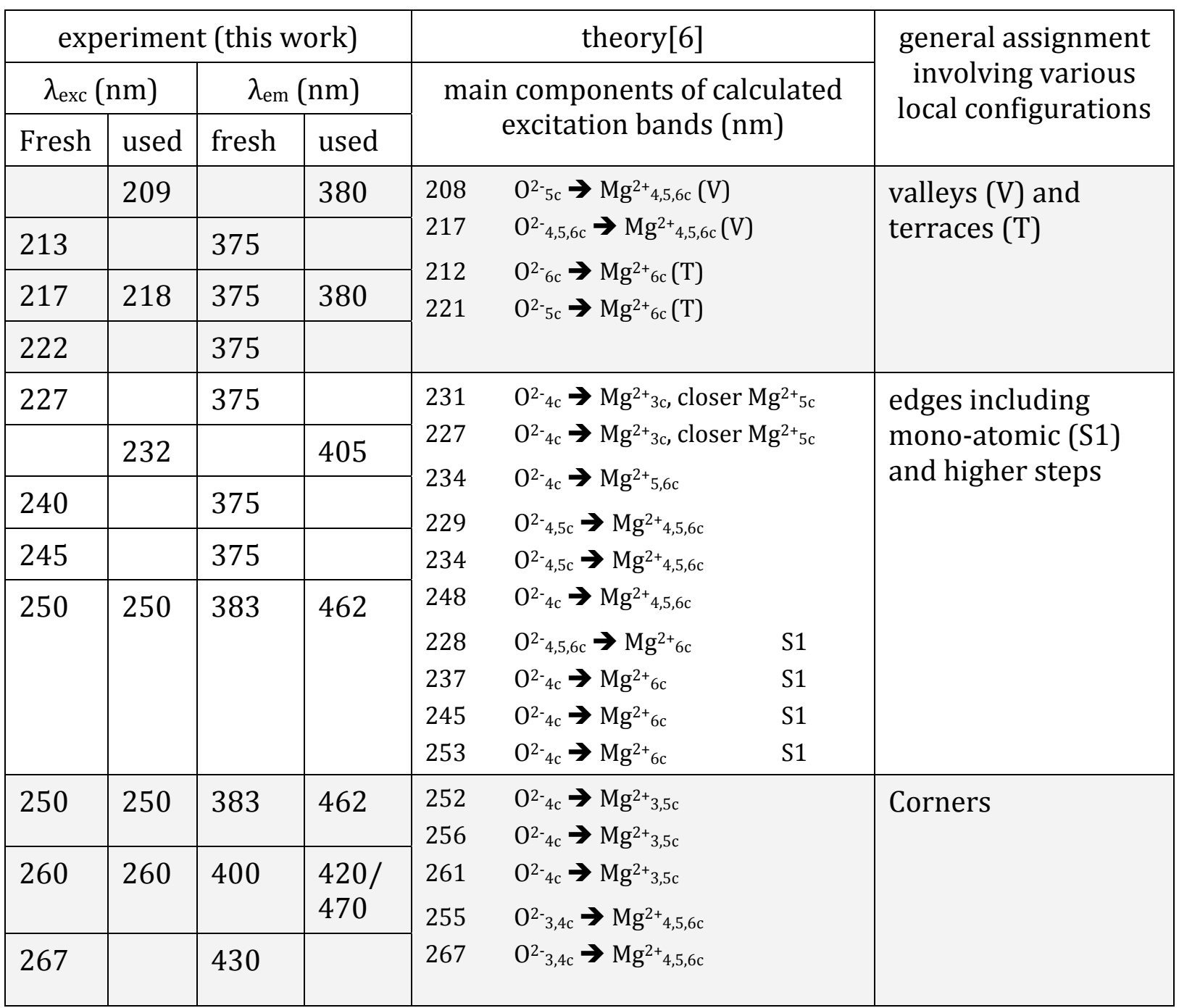




\subsection{EPR spectroscopy}

Activation of methane or oxygen can lead to the formation of paramagnetic species like $\mathrm{CH}_{3}{ }^{\bullet}$ or $\mathrm{O}_{2}^{-}$radicals, which can be probed by electron paramagnetic resonance (EPR) spectroscopy.

Addition of molecular oxygen at room temperature after activation of $\mathrm{C}-\mathrm{MgO}$ at $1023 \mathrm{~K}$ in vacuum gives no signal in the EPR spectrum (Fig. 10a). However, upon simultaneous dosing of methane and oxygen at room temperature new signals in the spectrum can be observed (Fig. 10b). The obtained spectrum can be described best by anisotropic $g$ tensors that can be assigned to superoxide species.[27] The superoxide $\mathrm{O}_{2}{ }^{-}$is characterized by an orthorhombic symmetry with three principal $g$ values $g_{x x}, g_{y y}$ and $g_{z z}$ with the $z$ direction being that of the $\mathrm{O}_{2}{ }^{-}$intermolecular axis. The orthorhombic symmetry is due to the removal of the degeneracy between the two $\pi^{*}$ oxygen orbitals.[28] In the $\mathrm{g}_{\mathrm{zz}}$ region, three species are observed. The $\mathrm{g}_{\mathrm{zz}}$ value is very sensitive to the electrostatic field of the surrounding. Giamello et al. [29] found a linear correlation between the Madelung potential of the adsorbing cation and the $g_{z z}$ value of the superoxide. The high $g_{z z}$ value at 2.092 (denoted by $g_{z z}(A)$ ) and the lower $g_{z z}$ value at $2.074\left(\mathrm{~g}_{\mathrm{zz}}(\mathrm{B})\right)$ are generally assigned to superoxide formed at corners and mono-atomic steps, respectively.[29] The $\mathrm{g}_{\mathrm{zz}}$ signal at 2.085 was also measured by Murphy et al., but was not assigned to any morphological site.[30] The four well defined resonance lines in the $g_{x x}$ and $\mathrm{g}_{\mathrm{yy}}$ region are due to hyperfine coupling caused by the interaction of the superoxide ion with a proton in close vicinity and their hyperfine constants $A_{x x}(0.56 \mathrm{mT})$ and $A_{y y}(0.18 \mathrm{mT})$ are in agreement with literature values for superoxides formed on $\mathrm{MgO}$ upon simultaneous dosing of $\mathrm{O}_{2}$ and $\mathrm{H}_{2}$ at room temperature.[27] The formation of superoxide species may occur in an electron transfer reaction by dissociation of the polarized, and, therefore, slightly $\mathrm{C}-\mathrm{H}$ acidic adsorbed methane molecule under the final formation of a proton (or a hydroxyl group with a basic lattice oxygen atom), a methyl radical and the superoxide upon electron transfer from the splitted methane molecule to adsorbed molecular oxygen.[27] According to Diwald et al., 
superoxide species formed by charge transfer between hydrogen and molecular oxygen on $\mathrm{MgO}$ are located either on mono-atomic steps, or on oxygen vacancies situated at corners.[31] EPR signatures of methyl radicals were not found in our spectra, probably due to a fast desorption of these products already at room temperature.

Paganini et al. reported about heterolytic $\mathrm{C}-\mathrm{H}$ bond dissociation of saturated hydrocarbons including methane on the dehydroxylated $\mathrm{CaO}$ surface at room temperature, but on $\mathrm{MgO}$, dissociation was not observed.[32] The formed $\mathrm{CH}_{3}{ }^{-}$carbanion is able to transfer an electron either to co-adsorbed oxygen or to the $\mathrm{CaO}$ surface if irradiated by $\mathrm{UV}-\mathrm{Vis}$ light, thus forming superoxide $\mathrm{O}_{2}^{-}$species or $\mathrm{F}_{\mathrm{s}}(\mathrm{H})^{+}$color centers, respectively, and a methyl radical. In our experiments, no color centers were formed when $\mathrm{MgO}$ was irradiated in presence of adsorbed $\mathrm{CH}_{4}$. This result is in agreement with the IR spectroscopic experiments of $\mathrm{CH}_{4}$ adsorption on $\mathrm{MgO}$ that reveal a significant polarization of the $\mathrm{C}-\mathrm{H}$ bonds in methane, but no dissociation. Consequently, no electron transfer occurs at the surface of $\mathrm{MgO}$ in absence of oxygen. Instead, the adsorption of $\mathrm{CH}_{4}$ on $\mathrm{MgO}$ that contains structural defects with proper configuration weakens the $\mathrm{C}-\mathrm{H}$ bond, which allows the electrophilic attack by an oxygen molecule.

In summary, complementary EPR and FTIR measurements indicate that the MgO surface polarizes the $\mathrm{C}-\mathrm{H}$ bond in the adsorbed methane molecule (forming $\mathrm{H}_{3} \mathrm{C}-\mathrm{H}---\mathrm{O}-\mathrm{Mg}$ ), but that molecular oxygen is needed to finally break the bond via electron transfer from the polarized $\mathrm{CH}_{4}$ molecule to $\mathrm{O}_{2}$. It is remarkable, that this process occurs already at room temperature. 


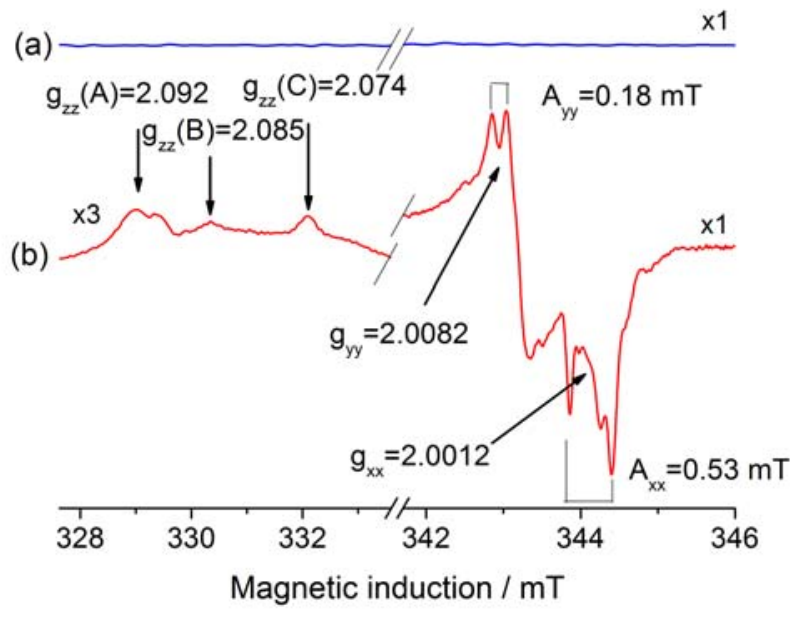

Fig. 10. C.W. X-band EPR spectra of C-MgO after evacuation at $1023 \mathrm{~K}$ in vacuum followed by (a) adsorption of $5 \cdot 10^{3} \mathrm{~Pa} \mathrm{O}_{2}$ at room temperature, and subsequent evacuation to a pressure of about $1 \cdot 10^{-4} \mathrm{~Pa}$, and (b) co-adsorption of $9 \cdot 10^{3} \mathrm{~Pa} \mathrm{CH}_{4}$ and $2 \cdot 10^{3} \mathrm{~Pa} \mathrm{O}_{2}$ at room temperature and subsequent evacuation to $1 \cdot 10^{-4} \mathrm{~Pa}$. The spectra were recorded at $77 \mathrm{~K}$.

\section{Discussion}

\subsection{Structural changes of the MgO surface during the OCM reaction}

The surface of $\mathrm{MgO}$ calcined at high temperature exhibits "localized" defects at the $\{100\}$ surface that contain coordinatively unsaturated sites (cus). Such structural defects comprise edges (at steps of different height) and corners. Their total concentration and relative abundance depend on the synthesis method. Differences in the synthesis technique are reflected in different initial activities and variations in the rate of catalyst deactivation[1] indicating that structural defects might be related to the catalytic activity of $\mathrm{MgO}$ in OCM. The strong deactivation of the catalyst under OCM conditions involves drastic changes in the primary particle morphology as observed by electron microscopy and spectroscopic techniques (Figs. 8, 9, and S3-S6).[1] There is clear experimental evidence for the disappearance of the $\{100\}$ cubic structure and the formation of high index crystal planes, like $\{110\}$ or $\{111\}$, or microfaceted structures due to sintering of the primary MgO particles. The sintering is caused by the reaction of the unavoidable reaction product water with the catalyst 
surface and leads to a dynamic change in the nature of the active sites, and, consequently, in the reaction mechanism with time on stream. The results of photoluminescence spectroscopy are in agreement with surface reconstructions under reaction conditions. The red shift (by 0.6 $\mathrm{eV}$ ) in the emission signal assigned to corners after use of $\mathrm{C}-\mathrm{MgO}$ indicates that the formation of polar, e.g., $\{111\}$ surfaces that exhibit an increased surface dipole moment in comparison to the $\{100\}$ surface, occurs (Fig. 9). Water formed in the OCM reaction may stabilize polar surfaces via the formation of $\mathrm{Mg}-\mathrm{OH}$ groups.[33] Since dehydroxylation of $\mathrm{MgO}$ is not yet complete at reaction temperature, the $\mathrm{MgO}$ surface in steady-state is at least partially covered by hydroxy groups. The $\mathrm{OH}$ groups formed under reaction conditions can also be regarded as impurity or dopant changing the Lewis acid-base properties of the catalyst surface. Furthermore, the presence of $\{111\}$ higher index planes on the surface of used $\mathrm{C}-\mathrm{MgO}$ is supported by IR spectroscopy. The number of corners determined by co-adsorption of CO and $\mathrm{CH}_{4}$ increases by using the material as catalyst (Fig. 7, blue bars).

In addition, the results of photoluminescence spectroscopy can be interpreted in terms of the formation of microfaceted surfaces. The $\{110\}$ surface can be regarded as an "infinite" array of mono-atomic steps in the $<110>$ direction of the crystal. If present on the surface of used $\mathrm{MgO}$ catalysts, the $\{110\}$ surface should cause a rise of intensity of the signals at 240 and 245 $\mathrm{nm}$ in the excitation spectra. However, by using $\mathrm{C}-\mathrm{MgO}$ in $\mathrm{OCM}$, extinction of these signals and an increase in the signals due to polyatomic steps and valleys is observed suggesting the formation of micro-facets. The formation of micro-faceted surfaces is driven by thermodynamics. Based on the Born model of solids, de Leeuw et al. calculated that microfaceted $\{110\}$ surfaces have a lower surface energy than the planar $\{110\}$ surface.[33]

The drastic changes of the catalyst surface with time on stream imply changes in the reaction mechanism. In the following, the catalytic properties of $\mathrm{MgO}$ in OCM will be discussed in 
two parts dealing at first with the fresh $\mathrm{MgO}$ surface (Chapter 4.2) and secondly with the $\mathrm{MgO}$ surface under steady-state conditions (Chapter 4.3).

\subsection{Activation of methane on the fresh dehydroxylated MgO surface at $t=0$}

In the following, we combine the spectroscopic results reported above with kinetic data summarized in [1] to develop a model for methane activation at the surface of dehydroxylated $\mathrm{MgO}$ that shows very high activity far from steady-state operation. The spectroscopic characterization of the fresh catalyst surface describes a situation, which comes across the reactants at the very beginning of the reaction (at $t=0$ ). The magnesium oxides involved in the present study are comparatively rich in edges and corners present on the $\{100\}$ surface that have been semi-quantitatively determined by FTIR spectroscopy of adsorbed CO and methane. The edges expose $\mathrm{Mg}^{2+}-\mathrm{O}^{2-}$ acid-base pairs, which are considered as dihapto adsorption sites for methane (Scheme 1), while on corners, the methane molecule is adsorbed on a single oxygen or magnesium ion. By plotting the rate of methane consumption and the rate of $\mathrm{C}_{2+}$ formation at $t=0$ as a function of the relative abundance of edges related to the total number of adsorption sites (edges plus corners) on the surface of the freshly pretreated catalysts, a clear correlation is observed showing the relevance of edges (Lewis acid-base pairs) for selective activation of methane on $\mathrm{MgO}$ with the exception of S-MgO (Fig. 11). In the latter catalyst that was prepared by combustion of magnesium, the abundance of steps is very low and the edges basically represent the edges of the regular cubic particles. Here the peculiar situation happens that the relative amount of edges is very high in comparison to the amount of corners, but the total amount of edges, which belong to steps, is very low due to the quite regular surface structure of the $\mathrm{S}-\mathrm{MgO}$ particles. Mono-atomic steps do practically not exist on the surface of $\mathrm{S}-\mathrm{MgO}$. Our experimental findings are in good agreement with predictions by theory. In a series of recent theoretical papers, Metiu et al. emphasized the 
importance of strong Lewis acid-base pairs in the activation of methane through heterolytic C-

$\mathrm{H}$ bond dissociation and stabilization of the products on the surface of basic oxides.[34-36]

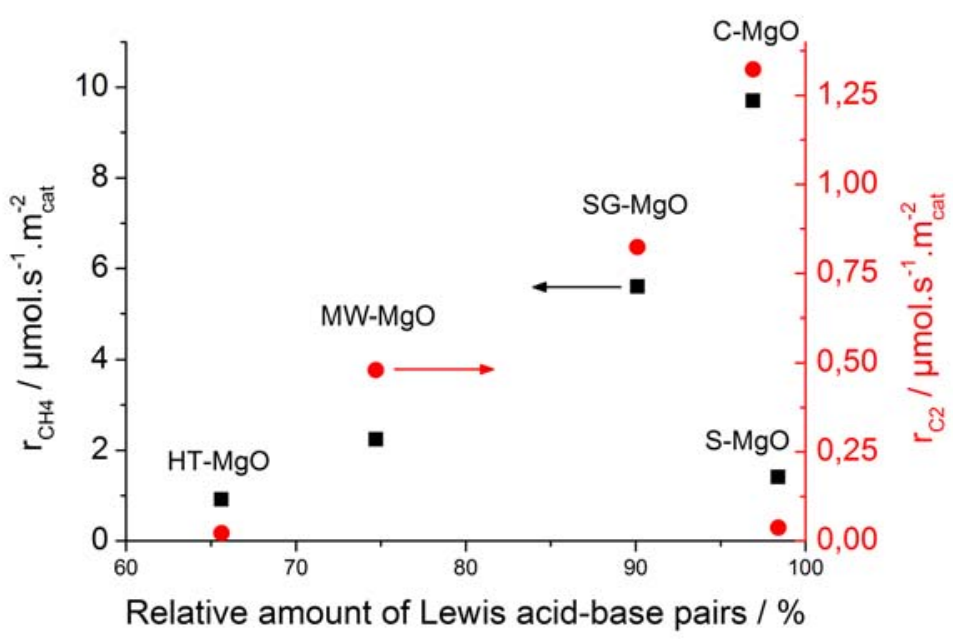

Fig. 11. Rate of methane consumption and $\mathrm{C}_{2+}$ formation at $t=0$ measured at $\mathrm{T}=1023 \mathrm{~K}$, applying a feed composition of $\mathrm{CH}_{4} / \mathrm{O}_{2} / \mathrm{N}_{2}=3 / 1 / 1$, and a contact time of $0.033 \mathrm{~g} \cdot \mathrm{s} \cdot \mathrm{ml}^{-1}$ as a function of the relative amount of acid-base pairs (edges) on the surface of the catalysts.

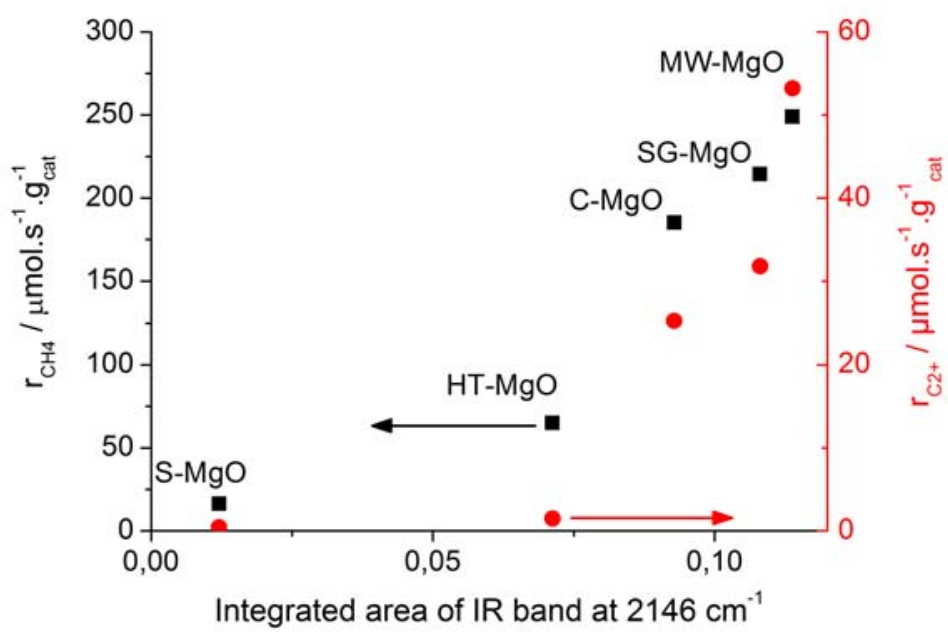

Fig. 12. Rate of methane consumption and $\mathrm{C}_{2+}$ formation at $t=0$ measured at $\mathrm{T}=1023 \mathrm{~K}$, applying a feed composition of $\mathrm{CH}_{4} / \mathrm{O}_{2} / \mathrm{N}_{2}=3 / 1 / 1$, and a contact time of $0.033 \mathrm{~g} \cdot \mathrm{s} \cdot \mathrm{ml}^{-1}$ plotted versus the integrated area of the $\mathrm{CO}$ adsorption peak at $2146 \mathrm{~cm}^{-1}$ that indicates the abundance of mono-atomic steps

When the rate of methane consumption is plotted as a function of the abundance of monoatomic steps, a clear trend is observed indicating that steps with a height that comprises one 
$\mathrm{Mg}-\mathrm{O}$ distance play an important role in the activation of methane (Fig. 12). The underlying analysis of the corresponding FTIR spectra is shown in Figs. S7-S12 and Tab. S1. Interestingly, Trionfetti et al. reported in agreement with our observations that the presence of step sites in $\mathrm{MgO}$ increases the number of active centers able to activate propane, however, in case of the propane molecule in an unselective way that leads to the formation of carbon oxides.[15] In calculations that model the surface of Na-doped $\mathrm{CaO}$, Sun et al.[36] have shown that the dissociation energy of the $\mathrm{C}-\mathrm{H}$ bonds are lowered when methane adsorption takes place on mono-atomic steps rather than on any other defect that contains lower coordinated ions.

Taking into account that (i) the oxygen partial pressure has a significant influence on the reaction rate,[1] and (ii) Lewis acid/base pairs on edges of mono-atomic steps are related to methane activation, a model for methane activation on the surface of pure, nano-structured and dehydroxylated $\mathrm{MgO}$ is proposed. The catalytic cycle is presented in Scheme 2. Thus, gas phase methane is adsorbed in a dihapto configuration on Lewis acid/base pairs located on mono-atomic steps on the surface of $\mathrm{MgO}$ (Steps $\mathrm{a}$, and $\mathrm{b}$ in Scheme 2). Co-adsorption of carbon monoxide and methane reveals that $\mathrm{CH}_{4}$ adsorbs preferentially in dihapto and to a lesser extent in monohapto configuration (Fig. 7, Scheme 1). In the second step, a C-H bond of the methane molecule is polarized as observed by IR spectroscopy of adsorbed $\mathrm{CH}_{4}$ and $\mathrm{CD}_{4}$ on $\mathrm{MgO}$ (Figs. 5-6). The adsorbed methane molecule bends towards the terrace at the bottom of the mono-atomic step, which allows the interaction of $\mathrm{H}$ atoms of methane with basic lattice oxygen resulting in $\mathrm{C}-\mathrm{H}$ bond elongation, i.e., strong polarization of $\mathrm{C}-\mathrm{H}$ bonds (Step c in Scheme 2). The interaction of hydrogen atoms of adsorbed methane and oxygen atoms at the terrace is reflected in the appearance of bands due to O-H (or O-D) stretching vibrations after adsorption of (deuterated) methane at $77 \mathrm{~K}$ (Figs. 5-6). The underlying interaction is week, since the adsorption at $77 \mathrm{~K}$ is reversible and no heterolytic dissociation 
was observed by adsorption of methane on $\mathrm{MgO}$ alone at this low temperature. This is in contrast to the properties of the stronger base $\mathrm{CaO}$. At the surface of calcium oxide methane dissociates heterolytically already at room temperature.[37] The dissociation of the C-H bond on $\mathrm{MgO}$ is, however, possible when molecular oxygen approaches and weakly adsorbs at the $\mathrm{MgO}$ surface near the adsorbed methane molecule (Step $\mathrm{d}$ in Scheme 2). The $\mathrm{C}-\mathrm{H}$ bond is broken in a concerted mechanism forming simultaneously a methyl radical and a superoxide $\mathrm{O}_{2}{ }^{-}$species (Step e in Scheme 2). Evidently, the oxygen molecule is able to accept an electron from the adsorbed methane molecule. The methyl radical formed is not stable at the surface of $\mathrm{MgO}$ and is released to the gas phase. Alternatively (or in parallel), a surface mediated coupling of two simultaneously activated methane molecules adsorbed at neighboring sites and the subsequent formation of the $\mathrm{C}_{2}$ product ethane and hydrogen peroxide may happen without desorption of methyl radicals.[1] The latter option may prevail at the high reaction temperature, whereas the occurrence of $\mathrm{O}_{2}{ }^{-}$species after contact of $\mathrm{C}-\mathrm{MgO}$ with a reaction mixture of methane and oxygen has been confirmed by EPR spectroscopy already at room temperature (Fig. 10). Hyperfine coupling of the superoxide anion with a proton in close proximity suggests heterolytic $\mathrm{C}-\mathrm{H}$ bond dissociation on mono-atomic steps of $\mathrm{MgO}$ at room temperature. This is in agreement with DFT calculations.[38] The active site is regenerated by desorption of the perhydroxyl radical $\mathrm{HO}_{2}{ }^{\bullet}$, which may initiate further homogeneous reactions by, e.g., hydrogen abstraction from methane molecules in the gas phase.[39] The increasing $\mathrm{CO}_{2} / \mathrm{CO}$ ratio observed with increasing methane conversion[1] could be attributed to the formation of $\mathrm{HO}_{2}{ }^{\circ}$ radicals in the gas phase according to reaction (1). Reaction (1) would also explain the strong decrease in the $\mathrm{CO}_{2} / \mathrm{CO}$ ratio with time on stream that goes along with the fast disappearance of mono-atomic steps, on which the mechanism proposed in Scheme 2 is predominant.

$\mathrm{CO}+\mathrm{HO}_{2}^{\cdot} \rightarrow \mathrm{CO}_{2}+\mathrm{OH}^{\cdot}$ 


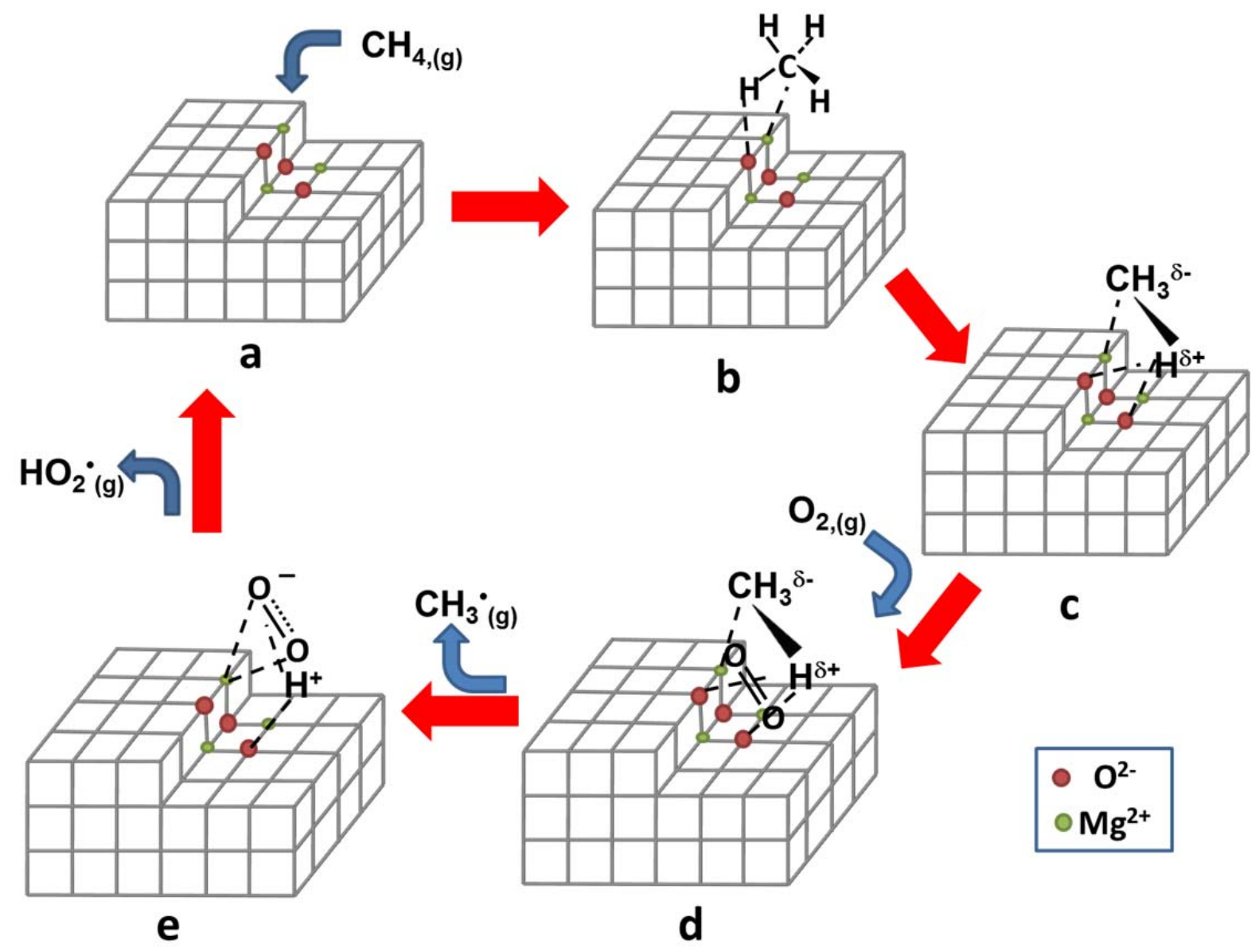

Scheme 2. Proposed mechanism of methane activation on fresh dehydroxylated $\mathrm{MgO}$.

The mechanistic concept proposed in Scheme 2 provides an explanation for the high reaction temperatures that are required. The high temperature is, apparently, in conflict with the observation that methane can be activated already at room temperature on the surface of $\mathrm{MgO}$ (Figs. 5, 6, and 10). Perhydroxyl radicals are precursors for the formation of hydroxy groups and water, which may lead to deactivation of $\mathrm{MgO}$ by sintering. Once the surface is covered with adsorbed hydroxy groups, methane cannot adsorb anymore, unless high reaction temperatures are applied to assure a partially dehydroxylated surface under reaction conditions. In addition, Ito et al. reported that methyl radicals from the gas phase could react with surface oxygen under formation of strongly bonded methoxide species[40] according to 
eq. (2). Lunsford et al. confirmed that the sticking coefficient of methyl radicals on metal oxide surfaces drastically increase in the presence of oxygen in the gas phase due to the formation of methoxide ions according to eq. (3).[41] Methoxide species can be transformed into carbonates at room temperature and decompose only at high temperature $(\mathrm{T}>700 \mathrm{~K})$ to produce either syngas or carbon dioxide and water.[40] Equation (3) is, therefore, one route to total oxidation during the OCM reaction.

$$
\begin{aligned}
& \mathrm{CH}_{3}{ }^{-}+\mathrm{O}^{2-} \rightarrow \mathrm{CH}_{3} \mathrm{O}^{-}+\mathrm{e}^{-} \\
& \mathrm{CH}_{3}{ }^{\bullet}+\mathrm{O}_{2}+\mathrm{O}^{2-}{ }_{\mathrm{s}} \rightarrow \mathrm{CH}_{3} \mathrm{O}^{\bullet-}{ }_{\mathrm{s}}+\mathrm{O}_{2}^{-} \rightarrow \rightarrow \rightarrow \mathrm{CO}_{\mathrm{s}}
\end{aligned}
$$

\subsection{Active sites under steady-state conditions}

Mono-atomic step edges disappear in the used catalysts (Figs. 8 - 9). The decrease in specific surface area, the increase in $\mathrm{MgO}$ domain size, as well as the degradation of the cubic $\{100\}$ structure evidence sintering processes of the primary $\mathrm{MgO}$ particles during time on stream under conditions of the OCM reaction.[1]

Water vapor at reaction temperature induced the stabilization of high index plane surface terminations as shown by $2 \mathrm{D}$ photoluminescence spectroscopy (Fig. 9). Theoretical calculations show that $\mathrm{MgO}$ experiences surface reconstruction at high water coverage forming thermodynamically stable hydroxylated $\{111\}$ surfaces.[33, 42] Water is preferentially adsorbed on mono-atomic steps or $\{310\}$ like planes.[33, 43] In this respect, water vapor acts as a catalyst poison destroying the highly active mono-atomic steps identified on the surface of the freshly dehydroxylated $\mathrm{MgO}$ catalysts. Under reaction conditions of the oxidative coupling of methane, pure $\mathrm{MgO}$ is transformed into a dynamic phase mixture of $\mathrm{MgO}$ and $\mathrm{Mg}(\mathrm{OH})_{2}$. By electron microscopy, the formation of more rounded particles, which are terminated by higher index planes, is observed for all $\mathrm{MgO}$ catalysts.[1] The closely related particle morphology of the used catalysts is in agreement with similar 
methane conversions in steady-state over the differently prepared magnesium oxides. Consequently, the nature of the actives sites and, accordingly, the reaction mechanism changes with time on stream.

The interaction of water vapor with $\mathrm{MgO}$ is the driving force for the formation of point defects either on the surface or in the bulk of the oxide. Point defects, involving hydroxy groups adjacent to a magnesium vacancy $\left(\mathrm{V}_{\mathrm{OH}}\right.$-like centers or $\left(V_{M g}^{\prime \prime} O H^{\bullet}\right)^{\prime}$-equivalent centers $)$ are presumably important for the catalytic activity of $\mathrm{MgO}$ in the stationary state, since they are the precursors for the formation of $\mathrm{O}^{-}$sites (positive holes bound to an oxygen lattice $\mathrm{O}^{2-}$ ion $\left.\left(O^{2-}+h^{\bullet}=O^{-}\right)\right)$, which, perhaps, are present as triangular $\mathrm{O}^{-}$arrays of the $\{111\}$ planes.[44] The $\mathrm{O}^{-}$centers have been taken into account as sites for the activation of small alkane molecules or hydrogen.[45, 46] In the same way, the incorporation of excess oxygen into $\mathrm{MgO}$ leads to the formation of cation vacancies and $\mathrm{O}^{-}$anions $\left(\mathrm{Mg}^{2+} \mathrm{O}^{2-}+\partial \mathrm{O}_{2}=\mathrm{Mg}^{2+} \mathrm{O}_{1-\partial}^{2-}\left(\mathrm{O}^{-}\right)_{2 \partial}\right) \cdot$ [47] The formation of $\mathrm{Mg}$ vacancies and positive holes were experimentally confirmed by conductivity measurements of $\mathrm{MgO}$ in the presence of oxygen at high temperature. $[48,49]$ However the addition of carbon dioxide to the OCM feed does not affect the reactivity at steady state. $\mathrm{CO}_{2}$ is known to react strongly with $\mathrm{O}^{-}$species to form carbonate species. In the case of $\mathrm{Li}$ doped $\mathrm{MgO}, \mathrm{CO}_{2}$ is considered as a poison for the catalyst.[50, 51] Again, the high reaction temperatures may be responsible for maintenance of activity due to the decomposition of carbonates.

Hence, the situation at steady-state is much more complicated than on fresh $\mathrm{MgO}$ catalysts. The cubic $\{100\}$ structure and mono-atomic steps have vanished and the surface of the catalyst exhibits higher index planes or micro-facets. At the same time, different species are adsorbed on the catalysts surface changing its reactivity and electronic properties. For instance, adsorbed protons on lattice oxygen change the basicity of the $\mathrm{MgO}$ surface as 
emphasized by Metiu et al.[34, 35] Activated oxygen (like superoxide) adsorbed on the surface may also be reactive in the OCM reaction. At the same time, the change in the $\mathrm{MgO}$ morphology due to water vapor induces the formation of point defects that can also change the reactivity.

It appears that at steady-state the OCM reaction over $\mathrm{MgO}$ is less structure sensitive than on fresh $\mathrm{MgO}$ catalysts, explaining the relative similar activity of the five differently prepared pure $\mathrm{MgO}$ catalysts despite differences in the surface structure (Figs. 9, S4, S6).[1] The surfaces of the higher index planes offer strong adsorption sites for methane allowing perhaps different mechanisms of $\mathrm{C}-\mathrm{H}$ bond polarization. Based on the current experimental results, however, only speculations are possible. A deeper understanding of the situation under steady-state conditions requires further investigations.

\section{Conclusions}

Oxidative coupling of methane on the surface of magnesium oxide is a dynamic and structure sensitive process. With time on stream the nature of active sites changes and different reaction pathways that differ in the mode of activating methane and oxygen may happen in parallel.

On the freshly activated, nano-structured and dehydroxylated magnesium oxide surface, methane coupling occurs through intermolecular charge transfer between methane adsorbed on acid-base pairs located at edges of mono-atomic steps and weakly adsorbed oxygen approaching from the gas phase. Mono-atomic step edges offer an optimal configuration for the adsorption of methane and the polarization of its $\mathrm{C}-\mathrm{H}$ bonds. The mechanism is in accordance with the semi-quantitative correlation between active site concentration determined by FTIR spectroscopy and reaction rate, and supported by the detection of $\mathrm{O}_{2}^{-}$ species by EPR spectroscopy, as well as the strong relation between methane consumption rate and oxygen partial pressure observed in the kinetic study.[1] The outcome of the present 
study implies a design concept of highly active sites for methane activation. However, the corresponding sites are not stable, since the mechanism is self-inhibited by formation of the by-product water and the destruction of the active sites, which are preferentially attacked by water vapor at the high reaction temperatures.

The $\mathrm{MgO}$ particles sinter due to the presence of water and the high temperature. The sintering process occurs through the formation of magnesium vacancies. On the one hand, once the surface energy of the $\mathrm{MgO}$ is minimized under OCM reaction condition in the stationary state, the formation of magnesium vacancies due to water incorporation is supposed to be marginal since the OCM feed becomes increasingly oxidizing. On the other hand, the high concentration of oxygen may lead to the formation of $\mathrm{V}^{-}$centers due to the excess of oxygen incorporation and formation of $\{111\}$ microfacets. Systematic studies of the deactivation and sintering process are, however, required to deliver more detailed inside into the activation of methane and oxygen and the nature of the active sites under stationary conditions.

Since water is an unavoidable reaction product, the stabilization of mono-atomic steps is not trivial. Therefore, alternative strategies should also be considered in the design of stable catalysts for OCM. Recently, the formation of strongly bound $\mathrm{O}_{2}{ }^{-}$species, the precursors of dissociatively adsorbed $\mathrm{O}_{2}$, has been observed on single-crystal $\mathrm{CaO}$ films doped with $\mathrm{Mo}^{2+}$ ions.[52] Such an electronic doping does not require any surface structural defects. The concept, which is also applicable to powder catalysts, $[52,53]$ provides another promising approach to active and stable OCM catalysts.

\section{Acknowledgements}

This work was conducted in the framework of the COE "UniCat" (www. unicat.tu-berlin.de) of the German Science Foundation. The authors thank Jutta Kröhnert for her help with the 
conduction of IR experiments.

\section{References}

[1] P. Schwach, W. Frandsen, M.G. Willinger, R. Schlögl, A. Trunschke, Journal of Catalysis, submitted (2015).

[2] G. Spoto, E.N. Gribov, G. Ricchiardi, A. Damin, D. Scarano, S. Bordiga, C. Lamberti, A. Zecchina, Progress in Surface Science, 76 (2004) 71-146.

[3] A.M. Ferrari, S. Huber, H. Knozinger, K.M. Neyman, N. Rosch, Journal of Physical Chemistry B, 102 (1998) 4548-4555.

[4] M. Anpo, M. Che, Applications of photoluminescence techniques to the characterization of solid surfaces in relation to adsorption, catalysis, and photocatalysis, in: W.O. Haag, B.C. Gates, H. Knozinger (Eds.) Advances in Catalysis, Vol 44, 1999, pp. 119-257.

[5] C. Chizallet, G. Costentin, J.-M. Krafft, H. Lauron-Pernot, M. Che, Kinetic Model of Energy Transfer Processes Between Low-Coordinated Ions on $\mathrm{MgO}$ by Photoluminescence Decay Measurements, in, 2006, pp. 904-911.

[6] C. Chizallet, G. Costentin, H. Lauron-Pernott, J.-M. Krafft, M. Che, F. Delbecq, P. Sautet, Journal of Physical Chemistry C, 112 (2008) 16629-16637.

[7] R. Hacquart, J.-M. Krafft, G. Costentin, J. Jupille, Surface Science, 595 (2005) 172-182.

[8] S. Stoll, A. Schweiger, Journal of Magnetic Resonance, 178 (2006) 42-55.

[9] K.I. Hadjiivanov, G.N. Vayssilov, Characterization of oxide surfaces and zeolites by carbon monoxide as an IR probe molecule, in: Advances in Catalysis, Vol 47, Academic Press Inc, San Diego, 2002, pp. 307-511.

[10] N.S. Hush, M.L. Williams, Journal of Molecular Spectroscopy, 50 (1974) 349-368.

[11] G. Pacchioni, G. Cogliandro, P.S. Bagus, International Journal of Quantum Chemistry, 42 (1992) 1115-1139.

[12] M.A. Babaeva, D.S. Bystrov, A.Y. Kovalgin, A.A. Tsyganenko, Journal of Catalysis, 123 (1990) 396-416.

[13] E. Guglielminotti, S. Coluccia, E. Garrone, L. Cerruti, A. Zecchina, Journal of the Chemical Society, Faraday Transactions 1: Physical Chemistry in Condensed Phases, 75 (1979) 96-108.

[14] R. Soave, G. Pacchioni, Chemical Physics Letters, 320 (2000) 345-351.

[15] C. Trionfetti, I.V. Babich, K. Seshan, L. Lefferts, Langmuir, 24 (2008) 8220-8228.

[16] U. Zavyalova, G. Weinberg, W. Frandsen, F. Girgsdies, T. Risse, K.P. Dinse, R.

Schloegl, R. Horn, ChemCatChem, 3 (2011) 1779-1788.

[17] A.M. Ferrari, S. Huber, H. Knözinger, K.M. Neyman, N. Rösch, The Journal of Physical Chemistry B, 102 (1998) 4548-4555.

[18] C. Li, G. Li, Q. Xin, The Journal of Physical Chemistry, 98 (1994) 1933-1938.

[19] N. Sheppard, D.J.C. Yates, Proceedings of the Royal Society of London. Series A.

Mathematical and Physical Sciences, 238 (1956) 69-89.

[20] E. Knözinger, K.-H. Jacob, S. Singh, P. Hofmann, Surface Science, 290 (1993) 388-402.

[21] J.D. Levine, P. Mark, Physical Review, 144 (1966) 751-\&.

[22] E. Garrone, A. Zecchina, F.S. Stone, Philosophical Magazine B-Physics of Condensed

Matter Statistical Mechanics Electronic Optical and Magnetic Properties, 42 (1980) 683-703.

[23] S. Coluccia, A.M. Deane, A.J. Tench, Journal of the Chemical Society, Faraday

Transactions 1: Physical Chemistry in Condensed Phases, 74 (1978) 2913-2922.

[24] S. Benedetti, H.M. Benia, N. Nilius, S. Valeri, H.J. Freund, Chemical Physics Letters, 430 (2006) 330-335. 
[25] P.V. Sushko, A.L. Shluger, Surface Science, 421 (1999) L157-L165.

[26] S. Coluccia, A.J. Tench, R.L. Segall, Journal of the Chemical Society-Faraday Transactions I, 75 (1979) 1769-\&.

[27] E. Giamello, E. Garrone, P. Ugliengo, M. Che, A.J. Tench, Journal of the Chemical Society-Faraday Transactions I, 85 (1989) 3987-3994.

[28] M. Che, A.J. Tench, Advances in Catalysis, 32 (1983) 1-148.

[29] E. Giamello, P. Ugliengo, E. Garrone, Journal of the Chemical Society, Faraday

Transactions 1: Physical Chemistry in Condensed Phases, 85 (1989) 1373-1382.

[30] D.M. Murphy, R.D. Farley, I.J. Purnell, C.C. Rowlands, A.R. Yacob, M.C. Paganini, E. Giamello, Journal of Physical Chemistry B, 103 (1999) 1944-1953.

[31] O. Diwald, E. Knozinger, Journal of Physical Chemistry B, 106 (2002) 3495-3502. [32] M.C. Paganini, M. Chiesa, P. Martino, E. Giamello, E. Garrone, Journal of Physical Chemistry B, 107 (2003) 2575-2580.

[33] N.H. de Leeuw, G.W. Watson, S.C. Parker, The Journal of Physical Chemistry, 99 (1995) 17219-17225.

[34] Z. Hu, B. Li, X. Sun, H. Metiu, Journal of Physical Chemistry C, 115 (2011) 3065-3074.

[35] H. Metiu, S. Chretien, Z. Hu, B. Li, X. Sun, Journal of Physical Chemistry C, 116 (2012)

10439-10450.

[36] X. Sun, B. Li, H. Metiu, Journal of Physical Chemistry C, 117 (2013) 7114-7122.

[37] M.C. Paganini, M. Chiesa, P. Martino, S. Livraghi, E. Giamello, An EPR study of the surface reactivity of $\mathrm{CaO}$ and a comparison with that of $\mathrm{MgO}$, in: A. Gamble, C. Colella, S. Coluccia (Eds.) Oxide Based Materials: New Sources, Novel Phases, New Applications, 2005, pp. 441-449.

[38] K. Kwapien, J. Paier, J. Sauer, M. Geske, U. Zavyalova, R. Horn, P. Schwach, A. Trunschke, R. Schlögl, Angewandte Chemie International Edition, (2014) n/a-n/a.

[39] M. Iwamoto, J.H. Lunsford, The Journal of Physical Chemistry, 84 (1980) 3079-3084.

[40] T. Ito, T. Watanabe, T. Tashiro, K. Toi, Journal of the Chemical Society-Faraday Transactions I, 85 (1989) 2381-2395.

[41] M.T. Xu, T.H. Ballinger, J.H. Lunsford, Journal of Physical Chemistry, 99 (1995) 14494-14499.

[42] K. Refson, R.A. Wogelius, D.G. Fraser, M.C. Payne, M.H. Lee, V. Milman, Physical Review B, 52 (1995) 10823-10826.

[43] D. Costa, C. Chizallet, B. Ealet, J. Goniakowski, F. Finocchi, J. Chem. Phys., 125 (2006).

[44] M. Boudart, A. Delbouille, E.G. Derouane, V. Indovina, A.B. Walters, Journal of the American Chemical Society, 94 (1972) 6622-6630.

[45] K. Aika, J.H. Lunsford, The Journal of Physical Chemistry, 81 (1977) 1393-1398.

[46] D.J. Driscoll, W. Martir, J.X. Wang, J.H. Lunsford, Journal of the American Chemical Society, 107 (1985) 58-63.

[47] H. Kathrein, F. Freund, J. Nagy, Journal of Physics and Chemistry of Solids, 45 (1984) 1155-1163.

[48] D.R. Sempolinski, W.D. Kingery, Ionic Conductivity and Magnesium Vacancy Mobility in Magnesium Oxide, in, 1980, pp. 664-669.

[49] D.R. Sempolinski, W.D. Kingery, H.L. Tuller, Electronic Conductivity of Single Crystalline Magnesium Oxide, in, 1980, pp. 669-675.

[50] E. Kondratenko, M. Baerns, Oxidative Coupling of Methan in G. Ertl, F. Schüth, J.

Weitkamp (Ed.), Handbook of Heterogeneous Catalysis, Wiley-VCH, 2008, pp. 3010-3023. [51] L. Leveles, K. Seshan, J.A. Lercher, L. Lefferts, Journal of Catalysis, 218 (2003) 296306. 
[52] Y. Cui, X. Shao, M. Baldofski, J. Sauer, N. Nilius, H.-J. Freund, Angewandte Chemie International Edition, 52 (2013) 11385-11387.

[53] P. Schwach, M.G. Willinger, A. Trunschke, R. Schlögl, Angewandte Chemie International Edition, 52 (2013) 11381-11384. 